\title{
DEBER DE CONGRUENCIA (RECTIUS, CORRELACIÓN) DE LA SENTENCIA PENAL Y OBJETO DEL PROCESO: UN PROBLEMA NO RESUELTO EN LA LEY E INSOLUBLE PARA LA JURISPRUDENCIA CHILENA* MATCHING DUTY (RECTIUS, CORRELATION) OF THE JUDGEMENT AND THE SUBJECT OF THE CRIMINAL PROCEDURE: AN UNRESOLVED PROBLEM IN THE LAW AN INSOLUBLE FOR THE CHILEAN JURISPRUDENCE
}

\author{
Carlos del Río Ferretti**
}

\begin{abstract}
RESUMEN
El presente estudio trata del deber de correlación de la sentencia penal y los problemas de su aplicación presentados en la jurisprudencia (y doctrina) chilena. El tema es analizado fijando el supuesto técnico previo sobre el cual se construye dicho deber, como es la determinación del objeto del proceso a partir de un preciso concepto del hecho punible desde una perspectiva procesal. Es por ello que se analizan las posiciones teóricas y técnicas sobre el concepto del hecho, más apropiadas para responder a las complejas cuestiones comprendidas en el deber de correlación de la sentencia penal, destinadas a resolver los problemas de aplicación explicados en el estudio. Con ese propósito se analizan las teorías naturalistas y normativas del hecho y se intenta demostrar las repercusiones prácticas de sus respectivas aplicaciones.
\end{abstract}

\begin{abstract}
This research is about the matching duty of the criminal judgement and problems that come along with its application by the chilean tribunals (and Literature). The topic is analyzed setting the technical support after which builds on that
\end{abstract}

El presente estudio es resultado del proyecto FONDECYT No 11075090 , concedido al autor. Trabajo recibido el 20 de agosto de 2008; aprobada su publicación el 7 de noviembre de 2008.

** Doctor en Derecho por la Universidad de Valencia (España) y profesor de Derecho procesal de la Escuela de Derecho de la Universidad Católica del Norte. 
obligation, as in the definition of the subject of the criminal procedure from a precise concept of the punishable act from a procedural perspective. This is the reason why we study the technical and theoretical positions about the concept of «fact» more appropriate to understand the complex issue that involves the matching duty of the criminal judgement, to resolve the problems that come along with is application as we explain in this study. To this purpose we analyze naturalists and normatives theories about the concept of «fact» and intend proving the practical consequence wether you submit to one or another theory.

\section{PALABRAS CLAVES:}

Proceso penal, congruencia, correlación, objeto del proceso, hecho procesal, hecho punible, teoría naturalista, teoría normativa, objeto del debate.

\section{KEY WORDS:}

Criminal procedure, matching, correlation, subject of the procedure, naturalist theory, normative theory, subject of debate.

\section{EXPLICACIÓN PREVIA DEL DESARROLLO DOGMÁTICO Y JURISPRUDENCIAL CHILENO SOBRE EL HECHO COMO OBJETO DEL PROCESO Y CONTENIDO DEL DEBER DE CORRELACIÓN}

La jurisprudencia y la doctrina chilenas han sostenido mayoritariamente que el objeto del proceso se define por el hecho punible imputado al acusado. Esta forma de entender el objeto del proceso ha llevado como consecuencia que el deber de correlación de la sentencia se predique respecto del hecho punible.

Como derivación lógica de lo dicho, se ha excluido la utilidad de la calificación jurídica y del petitum a efectos de determinar la identidad del objeto del proceso. El argumento esencial radica en la idea de que corresponde al juez la facultad de enjuiciamiento jurídico, como se expresa en las reglas de da mihi factum, dabo tibi ius y de iura novit curia ${ }^{1}$. En otras palabras, la identidad del objeto del proceso se ha de ceñir al hecho, ya que la naturaleza de la función jurisdiccional implica la aplicación del Derecho penal al caso concreto, desprendiéndose de esto que debe ser el juzgador quien decida cuál es la solución jurídica del supuesto fáctico sometido a su decisión, es decir, la calificación jurídica e imponga la pena que corresponda

Vid. Agüero Herrera, M., Congruencia entre la acusación, la defensa y la sentencia. Editorial Universitaria, Santiago, 1965, pp. 87-89. 
Deber de congruencia (rectius, correlación) de la sentencia penal y objeto del proceso:

un problema no resuelto en la ley e insoluble para la jurisprudencia chilena

conforme a Derecho, de acuerdo a su interpretación jurídica, sin verse limitado por la calificación jurídica y el petitum de la acusación. Esta ha sido la posición uniforme de la jurisprudencia ${ }^{2}$.

A este argumento general se añadieron otros que tenían base legal positiva y que confirmaban que el objeto del proceso estaba constituido por el hecho punible. Nos referimos, en primer lugar, a consideraciones de hermenéutica legal. En efecto, el mismo art. 424 ACPP disponía que la acusación de oficio debiera dejar «testimonio de los hechos que constituyen el delito o los delitos», y lo mismo se establecía para la acusación particular, conforme al art. 427 ACPP. Ambas normas centraban la atención de la acusación en los hechos.

A estas normas de la acusación había que añadir un conjunto de normas legales que calzaban perfectamente con la tesis de la esencialidad del hecho punible: así básicamente los arts. 76, 102, 106 y 108 del ACPP, que hacían del hecho el fundamento del proceso penal ${ }^{3}$.

En efecto, el art. 76, que se refería al sumario, establecía que «todo juicio criminal a que dé origen la perpetración de un crimen o simple delito comenzará por la investigación de los hechos que constituyan la infracción (...)», declaración legal que centra la cuestión penal en lo fáctico, guardando perfecta armonía con los arts. 102 (desestimación de querella) y 106 (inicio del sumario de oficio). El art. 102, que regulaba la desestimación de la querella, ordenaba que el juez instructor debiera desestimarla cuando ésta se fundara en hechos no delictivos. En el caso del art. 106, que trataba del juez que tuviera conocimiento directo de un hecho punible, la norma disponía el deber de dictar la resolución de apertura del sumario denominada «auto cabeza de proceso» cuando este conocimiento del hecho se produjera. Se advierte, en consecuencia, que en las tres disposiciones citadas se miraba esencialmente al hecho punible como elemento medular del juicio criminal.

2 SSCS: Sentencia de 5 de junio de 1922, GT, 1922, $2^{\circ}$ semestre, $N^{\circ} 101$, p. 481; Sentencia de 25 de septiembre de 1944, GT, 1944, $2^{\circ}$ semestre, No 32, p. 151; Sentencia de 2 de noviembre de 1944, GT, $2^{\circ}$ semestre, $N^{\circ} 37$, p. 171; Sentencia de 9 de agosto de 1956, RDJC, tomo 53, secc. $4^{\circ}$, p. 92; Sentencia de 27 de julio de 1967, RDJC, tomo 64, secc. $4^{\circ}$, p. 161; Sentencia de 27 de octubre de 1967 , RDJC, tomo 64, secc. $4^{\circ}$, p. 302.

Especialmente importante es la SCA de Santiago, de 14 de enero de 1997, GJ, 1997, No 199, volumen 1, pp. 141-142, en la que se establece que la sentencia que se pronuncia sobre una atenuante no alegada por la defensa no incurre en ultra petita, porque el tribunal debe tenerla en cuenta de oficio desde que aparece en el proceso. El vicio sancionado por la ley consistía en que la sentencia se extendiera a puntos inconexos, situación que no podía producirse cuando el juez acogía o rechazaba una circunstancia modificatoria de responsabilidad (considerandos $1^{\circ}$ y $2^{\circ}$ ). Vid. también el análisis jurisprudencial de la reforma que hace Cortez Matcovich, G., El recurso de nulidad. Doctrina y jurisprudencia, segunda edición. LexisNexis, Santiago, 2006, pp. 274298. También se refiere a este asunto, aunque sumariamente, Rietourd Alvarado, A., El recurso de nulidad en el nuevo proceso penal. Editorial Jurídica de Chile, Santiago, 2007, pp. 75-77.

Sustenta esta opinión Fontecilla Riquelme, R., Tratado de Derecho procesal penal, tomo I, segunda edición. Editorial Jurídica de Chile, Santiago, 1978a, pp. 142-144. 
Más categórico aún era el contenido del art. 108, que señalaba expresamente que «La existencia del hecho punible es el fundamento de todo juicio criminal, y su comprobación por los medios que admite la ley es el primer objeto a que deben tender las investigaciones del sumario». Esta disposición termina por zanjar cualquier duda en la esfera legal de que el objeto del proceso penal estaba constituido por el hecho punible ${ }^{4}$.

En segundo lugar, al igual que en la doctrina española y alemana ${ }^{5}$, también se argumentó sobre la base de la necesidad de la unidad del concepto del objeto del proceso definido por el hecho punible, con exclusión de la calificación jurídica y del petitum, tanto para la determinación del deber de correlación como para la aplicación del principio del non bis in idem, que cobra vigor en la institución de la cosa juzgada penal ${ }^{6}$. Al respecto decía FONTECILLA RIQUELME ${ }^{7}$ : «surgen, pues, dos elementos relevantes, que constituyen la médula de la decisión que el juez debe hacer en la sentencia: el hecho punible y la persona a quien se atribuye la ejecución o participación de ese hecho».

«Sobre estos extremos versa el juzgamiento y determinan, por ende, la cosa juzgada».

«Por lo tanto, el concepto de identidad, del cual no podemos desprendernos, porque es de la esencia de la institución de la cosa juzgada que tiene por objeto evitar la repetición procesal, de lo que es idéntico, sólo puede surgir de la comparación del hecho y de la persona del procesado en el enfrentamiento de dos procesos».

Posición doctrinal que por lo demás contó posteriormente con expreso respaldo legal, ya que en el año 1991, con el fin de evitar cualquier problema interpretativo que se podía haber presentado en torno al genuino sentido de la cosa juzgada, generado por la ausencia de norma que lo resolviera expresamente, la Ley 19047 de 1991 introdujo una nueva redacción del art. 42 ACPP, el cual en su inciso $2^{\circ}$ recogía lo que en doctrina y jurisprudencia se venía concluyendo: «El procesado condenado, absuelto o sobreseído definitivamente por sentencia ejecutoriada, no podrá ser sometido a un nuevo proceso por el mismo hecho» ${ }^{8}$. Por lo tanto, si se predicaba la unidad del concepto objeto del proceso definido por el hecho, cabía entonces aplicar el mismo concepto de objeto a efectos de non bis in idem (efecto excluyente de cosa juzgada) como de correlación de la sentencia.

Así lo pone de relieve Fontecilla Riquelme, R., Tratado de Derecho procesal penal, tomo II, segunda edición. Editorial Jurídica de Chile, Santiago, 1978b, p. 144.

Vid. más adelante.

Coinciden en ello Fontecilla Riquelme (1978b) pp. 217-242, Agüero Herrera (1965) p. 15, y Meza Figueroa, P., De la ultra petita en el proceso penal chileno. Editorial Jurídica de Chile, Santiago, 1969 pp. 63-64.

Fontecilla Riquelme (1978b) pp. 231-232.

La norma subsiste en el art. 1 inciso $2^{\circ}$ del CPP. 
Deber de congruencia (rectius, correlación) de la sentencia penal y objeto del proceso:

un problema no resuelto en la ley e insoluble para la jurisprudencia chilena

Son estos los argumentos que priman -no siempre con claridad- en la posición de la jurisprudencia mayoritaria, la cual se pronunció por la inmutabilidad fáctica como el contenido propio de la correlación ${ }^{9}$.

Se estimó, por lo tanto, que la sentencia debía mantener la inmutabilidad del núcleo fáctico de la acusación, pues esa sería la forma de satisfacer el deber de correlación, excluyendo la posibilidad de que se juzguen otros hechos diferentes de los de la acusación ${ }^{10}$. Obviamos aquí de manera consciente el asunto que tiene que ver con el significado del deber de correlación de la sentencia con la acusación en un sistema inquisitivo como el que imperaba en Chile hasta antes de la reforma ${ }^{11}$.

SSCS: Sentencia de 7 de mayo de 1913, GT, 1913, 1er semestre, No 282, p. 887; Sentencia de 3 de junio de 1932, GT, 1932, 1er semestre, No 62, p. 201; Sentencia de 18 de abril de 1933, GT, 1933, 1er semestre, $N^{\circ} 53$, p. 241; Sentencia de 3 de junio de 1935, GT, 1935, 1er semestre, No 65, p. 301; Sentencia de 25 de mayo de 1937, GT, 1937, 1er semestre, N ${ }^{\text {0 } 75, ~ p . ~ 312 ; ~ S e n t e n c i a ~ d e ~} 1$ de septiembre de 1942, RCP., 1943, tomo 6, p. 195; Sentencia de 4 de agosto de 1943, RCP., 1943, tomo 6, p. 444; Sentencia de 9 de agosto de 1946, GT, $1946,2^{\circ}$ semestre, No 48 , p. 305 ; Sentencia de 15 de octubre de 1948 , GT, 1948, $2^{\circ}$ semestre, No 60 , p. 347 ; Sentencia de 10 de enero de 1952, RDJC, tomo 49, secc. 4ª p. 56; Sentencia de 9 de septiembre de 1953, RDJC, tomo 50, secc. $4^{\text {a }}$, p. 160; Sentencia de 6 de noviembre de 1961 , RDJC, tomo 58 , secc. $4^{\text {a }}$, p. 283 ; Sentencia de 17 de abril de 1963, RDJC, tomo 60, secc. 4a , p. 91; Sentencia de 6 de mayo de 1963, RDJC, tomo 60 , secc. $4^{\text {a }}$, p. 202; Sentencia de 4 de septiembre de 1963, RDJC, tomo 60, secc. 4a , p. 403; Sentencia de 14 de septiembre de 1964, RDJC, tomo 61, secc. 4a, p. 363; Sentencia de 13 de septiembre de 1966, RDJC, tomo 63, secc. $4^{\text {a }}$, p. 245; Sentencia de 27 de abril de 1967, RDJC, tomo 64, secc. 4a, p. 95; Sentencia de 26 de octubre de 1967, RDJC, tomo 64, secc. $4^{\mathrm{a}}$, p. 302; Sentencia de 1 de abril de 1968, RDJC, tomo 65, secc. $4^{\mathrm{a}}$, p. 63; Sentencia de 19 de abril de 1972, RDJC, tomo 69, secc. 4a, p. 31; Sentencia de 13 de noviembre de 1990, RDJC, tomo 87, secc. $4^{\text {a }}$, p. 133; Sentencia de 15 de diciembre de 1992, GJ, 1992, No 150 , volumen 2, pp. 6970; Sentencia de 15 de diciembre de 1992, FM, No 409, p. 949.

SSCA: Sentencia (CA de La Serena) de 28 de junio de 1940, RDJC, 1940, p. 181; Sentencia (CA de Santiago) de 7 de agosto de 1940, GT, 1940, $2^{\circ}$ semestre, No 96, p. 437; Sentencia (CA de Santiago) de 10 de noviembre de 1955, RDJC, tomo 52, secc. 4a , p. 114; Sentencia (CA de Temuco) de 11 de septiembre de 1964, RDJC, tomo 61, secc. 4a , p. 350; Sentencia (CA de Santiago) de 1 de agosto de 1984, GJ, 1984, No 49, pp. 116-117; Sentencia (CA de Santiago) de 19 de junio de 1986, RDJC, tomo 83, secc. 4a, p. 152; Sentencia (CA de Santiago) de 2 de julio de 1987, RDJC, tomo 84, secc. 4a , p. 98; Sentencia (CA de Santiago) de 19 de octubre de 1988, RDJC, tomo 85, secc. $4^{\text {a }}$, p. 180; Sentencia (CA de San Miguel) de 28 de septiembre de 1989, RDJC, tomo 86, secc. $4^{\mathrm{a}}$, p. 142; Sentencia (CA de Santiago) de 12 de septiembre de 1990, RDJC, tomo 87, secc. 4, p. 137; Sentencia (CA de Punta Arenas) de 16 de junio de 1993, RDJC, tomo 90, secc. 4a , p. 157; Sentencia (CA de Santiago) de 18 de abril de 1995, GJ, No 178, p. 133; Sentencia (CA de Santiago) de 22 de septiembre de 1995 , RDJC, secc. $4^{\text {a }}$, p. 248.

$10 \quad$ Agüero Herrera (1965) pp. 83-87.

11 La importancia y sentido del deber de correlación en un sistema inquisitivo han sido estudiados con detalle por Del Río Ferretti, C., La correlación de la sentencia con la acusación y la defensa. Estudio comparado del Derecho español con el chileno. Servicio de Publicaciones de la Universidad de Valencia, 2007, pp. 516 y ss. Claramente en un sistema inquisitivo no podemos encontrar el fundamento de la correlación en la vigencia del principio acusatorio, ya que éste se halla absolutamente ausente. Nótese, sin embargo, que en un sistema inquisitivo como era el chileno se establecía un deber de correlación de la sentencia con la acusación. Esa necesaria correspondencia entre ambos actos obedece no tanto al principio acusatorio como nosotros sostenemos ahora, sino más bien a una rudimentaria forma de asegurar la eficacia de la defensa del acusado. 
Pero el problema real no se presentó en la conclusión precedente: el objeto propio de la correlación es el hecho atribuido al acusado. La uniformidad preliminar que derivó de esta conclusión, en el sentido que el deber de correlación de la sentencia se satisface con la inmutabilidad del hecho en que se funda la acusación, se diluía al momento de dar el paso siguiente, esto es, cuando había que precisar la definición misma de hecho desde un punto de vista procesal penal, lo cual aparece como imprescindible para resolver de veras la cuestión de la identidad del objeto del proceso, pues de lo contrario toda la claridad inicial se acaba convirtiendo en una «claridad vacía de contenido» o formal.

La doctrina y jurisprudencia chilena no han desarrollado ningún criterio más o menos claro y estable para determinar cuándo el hecho es el mismo y cuándo uno sustancialmente distinto o nuevo. Del estudio de la jurisprudencia lo único que queda claro es que cada sentencia sigue un criterio casuístico del significado del concepto de hecho en el proceso penal.

Primeramente, la jurisprudencia tuvo que abordar el tema a partir de la consagración legal de la correlación, que se hallaba en el art. $541.10^{\mathrm{a}}$, razón por la cual hay que referirse a los términos específicos de que se sirvió la Ley para establecerla.

La redacción de la norma del art. 541.10a no se refirió en forma explícita y literal al deber de la sentencia de «guardar correlación con el hecho de la acusación», sino que utilizó unas expresiones distintas. Concretamente, decía que la sentencia no podía extenderse a «puntos inconexos con los que hubieren sido materia de la acusación y la defensa». El tenor de la norma, como se ve, no resolvía el problema de aclarar lo que era el hecho y, peor aún, suscitaba el problema añadido de determinar lo que debía de entenderse por «puntos inconexos».

Por eso podemos decir que en un sistema inquisitivo donde el que acusa es el mismo juzgador, el deber de correlación sólo se puede explicar y fundar en la necesidad, al menos formal, de reconocer el derecho de defensa y el principio de contradicción. Dejando aparte la cuestión de si se puede hablar realmente de un derecho de defensa efectiva y de la eficacia real del principio de contradicción en un sistema radicalmente inquisitivo y carente de terciedad, al menos formalmente había necesidad de reconocer al imputado el derecho de defensa y a controvertir los términos fácticos, jurídicos y probatorios de la acusación. En ese contexto el deber de correlación operaba como una norma de preclusión impuesta al juez-acusador, con lo cual la acusación una vez deducida por el juez acotaba los límites dentro de los cuales se iba a realizar la defensa, y se iba a contradecir y a debatir la prueba del plenario, de modo que el juez no podía ex post reformular los términos de la pretensión que debía enjuiciar. Su potestad pretensora había precluido en el mismo momento que la había ejercido y eso le marcaba unos límites al momento de tener que resolver.

Lo cierto es que el ACPP mantuvo la vigencia del deber de correlación de la sentencia, contemplándola como herramienta más o menos eficaz para tutelar el derecho de defensa del acusado frente a la acusación formulada por el instructor. Al acusado se le aseguraba que la acusación notificada que contenía el señalamiento de hechos jurídicamente calificados, atribuidos al acusado con un concreto grado de participación, no podía ser modificada sustancialmente en la sentencia, de manera que otorgaba la seguridad de conocimiento de la acusación y permitía articular la defensa pertinente. En otras palabras, el acusado tenía, por lo menos, derecho a contestar una acusación bien concretada y a ser juzgado sólo dentro de esa acusación previamente notificada y contestada. 
Deber de congruencia (rectius, correlación) de la sentencia penal y objeto del proceso:

un problema no resuelto en la ley e insoluble para la jurisprudencia chilena

Afortunadamente, se interpretó que la frase «puntos inconexos» era la fórmula legal que equivalía al concepto más técnico de «hechos»o, dicho en otros términos, la referencia a que la sentencia no puede extenderse a «puntos inconexos» era la forma como la norma se refería al concepto de «hechos sustancialmente distintos de los de la acusación o a otros hechos nuevos». No obstante lo expuesto, seguimos en el mismo punto: cuál era el concepto de hecho desde el punto de vista del proceso penal o cuál era el criterio que permitía distinguir cuándo el hecho era el mismo y cuándo había sido sustancialmente modificado en la sentencia.

Para alguna jurisprudencia ${ }^{12}$ se producía la infracción del deber de correlación cuando la sentencia se extendía a hechos que no habían sido debatidos, pero no ahondaba en este argumento de los hechos no debatidos en relación al deber de correlación. La consideración jurisprudencial se quedaba en una genérica estimación de «indefensión».

Otra jurisprudencia ${ }^{13}$ dice que se incurre en incongruencia cuando se condena por un delito de distinta especie, sin explicar mayormente qué entendía por esto. Se limitaba a dar una vaga referencia al bien jurídico protegido del delito que se estimaba en la sentencia, el cual no podía ser distinto del bien jurídico del delito que se imputaba en la acusación.

Un tercer grupo de sentencias ${ }^{14}$ señala que hay dicha infracción cuando los hechos establecidos en la sentencia no tienen relación o unión lógica con los que fueron objeto de la acusación. Curiosamente nunca se aclaró de forma específica qué significado tenía esta afirmación.

Si bien todas estas sentencias aportan algún elemento de juicio sobre los complejos problemas de la correlación, ninguna se preocupa de desarrollar una argumentación sólida sobre la institución en estudio, que permita resolver con cierta coherencia y fundamento los casos particulares que se han venido sometiendo a enjuiciamiento.

La jurisprudencia producida durante toda la vigencia del anterior Código nunca fue capaz de ofrecer una aproximación más o menos certera de lo que debía entenderse por «hecho», con el fin de determinar los alcances del deber de correlación.

Respecto a los criterios casuísticos que utilizó para resolver casos concretos tampoco supo explicarlos. La falta de adecuada motivación fáctica y jurídica probablemente sea una de

Por ejemplo, SCS de 10 de enero de 1952, RDJC, tomo 49, secc. $4^{\text {a }}$, p. 56.

Por ejemplo, SCS de 5 de junio de 1922, GT, 1922, $2^{\circ}$ semestre, $\mathrm{N}^{\circ} 101$, p. 481.

SSCS: Sentencia de 13 de septiembre de 1966, RDJC, tomo 63, secc. $4^{\text {a }}$, p. 245; Sentencia de 27 de abril de 1967, RDJC, tomo 64, secc. $4^{\text {a }}$, p. 95; Sentencia de 26 de octubre de 1967, RDJC, tomo 64, secc. $4^{\text {a }}$, p. 299 ; Sentencia de 15 de diciembre de 1992, FM, No 409, p. 949. 
las características más reprochables de la actividad jurisdiccional chilena ${ }^{15}$. Resultaba entonces que el deber de correlación de la sentencia consagrado en la Ley no pasaba de ser una «cláusula formal» que carecía de contenido. Su contenido era puesto en cada caso por el arbitrio del juez, quien con bastante poca precisión técnica valoraba genéricas y posibles «indefensiones» producidas por fallos que se extendían a «puntos inconexos».

Veamos lo que sucede con el modelo procesal de la Reforma. En el CPP hay dos disposiciones relevantes con miras a delinear el objeto del proceso: los arts. 1 y 341 . Los dos contienen la clave del objeto del proceso en el nuevo sistema.

El art. 341 es el que directamente regula la correlación. Este artículo nos ofrece una regulación que es clara al reglamentar el contenido del objeto del proceso con vista al deber de correlación, pues declara explícitamente qué elementos de la acusación deben ser respetados por la sentencia y qué otros, a pesar de ser parte de la acusación, no demandan la correspondencia de la sentencia.

El inciso $1^{\mathrm{o}}$ de la disposición señala que la «sentencia condenatoria no podrá exceder el contenido de la acusación. En consecuencia no se podrá condenar por hechos o circunstancias no contenidas en ella». Y añade y aclara en su inciso $2^{\circ}$ lo tocante a los otros contenidos de la acusación en relación con los poderes de calificación jurídica del juez, cuando agrega que el «tribunal podrá dar al hecho una calificación jurídica distinta de aquella contenida en la acusación o apreciar la concurrencia de causales modificatorias agravantes de la responsabilidad penal no incluidas en ella, siempre que hubiere advertido a los intervinientes durante la audiencia». Por consiguiente, queda claro que el concepto de objeto del proceso recogido en la Ley se define por el hecho punible y que se excluye del mismo a la calificación jurídica, dejándola en manos del tribunal en virtud de la facultad de la aplicación del Derecho, aunque condicionada por el presupuesto de eficacia de sometimiento a contradicción de la tesis de calificación del tribunal ${ }^{16}$.

Por otra parte, perfectamente coincidente con el objeto del proceso del art. 341 es el definido para la función excluyente o negativa de la cosa juzgada: principio del non bis in idem

15 En un trabajo monográfico se queja de este defecto de la jurisprudencia chilena el profesor Romero Seguel, A., Jurisprudencia de los tribunales como fuente del Derecho. Una perspectiva procesal. Editorial Jurídica de Chile, Santiago, 2004, pp. 105-107.

16 Esta forma de configuración guarda una evidente similitud con la del art. 322 del Código Procesal Penal Modelo para Iberoamérica. También con la StPO alemana, que en el § 265, que prevé los cambios de los puntos de vista jurídicos, consagra una norma muy parecida a la del CPP, pero más completa y rigurosa en la tutela del derecho de defensa. Asimismo la LECrime, que lo prevé en términos análogos o, mejor dicho, la interpretación dogmática de la LECrime, específicamente del art. 851.4 con relación al 733 y 788.3 y 4. 
Deber de congruencia (rectius, correlación) de la sentencia penal y objeto del proceso:

un problema no resuelto en la ley e insoluble para la jurisprudencia chilena

(y la litis pendencia) señalado en el art. 1 inciso final, que lo consagra como la proscripción del doble enjuiciamiento del mismo hecho, al declarar que «La persona condenada, absuelta o sobreseída definitivamente por sentencia ejecutoriada, no podrá ser sometida a un nuevo procedimiento penal por el mismo hecho».

Dicha disposición no es más que la casi exacta transcripción del art. 42 inciso $2^{\circ}$ del ACPP, que confirma el concepto de objeto del proceso a efectos de cosa juzgada, con lo cual tanto el derogado como el CPP vigente se mantienen dentro de lo que se conoce como la concepción unitaria del objeto del proceso ${ }^{17}$. Con esto el CPP, con aparente coherencia sistemática, sanciona un mismo objeto del proceso para la correlación como para las funciones de exclusión de nuevos procesos.

Resulta, sin embargo, que al llegar a la conclusión de que el objeto del proceso viene definido por el hecho punible y que la sentencia debe ser congruente con el hecho de la acusación no hacemos nada más que resolver el problema desde un punto de vista formal solamente, ya que seguimos sin saber en concreto con qué cosa ha de ser congruente la sentencia. Hemos dicho que para resolver esta cuestión hay que intentar establecer lo que sea el hecho punible desde el punto de vista procesal penal.

La cuestión demanda establecer cuáles son los criterios que desde un punto de vista procesal permiten determinar la identidad del hecho y que, por lo tanto, hacen posible discernir cuándo se ha operado una modificación en la sentencia que convierte al mismo en uno diverso del que se contenía en la acusación. Si no se sabe a ciencia cierta qué criterio define la identidad del hecho es «perfectamente imposible» establecer juicios de decisión uniformes que permitan determinar qué es lo que significa el deber de correlación ${ }^{18}$. La jurisprudencia del antiguo sistema operaba con criterios casuísticos que no obedecían, como hemos visto, a ningún orden teórico o, por lo menos, no se expresaba ninguno con una cierta coherencia. El problema amenaza con perpetuarse en el nuevo Código, pues la doctrina y la jurisprudencia todavía no se plantean el problema ${ }^{19}$. Es tan notoria la carencia en el medio jurídico chileno que, ciertas situaciones de una obviedad manifiesta, formuladas a los tribunales, han sido en su momento mal resueltas.

En efecto, la falta de criterios claros de lo que sea el hecho desde el punto de vista procesal penal (que no es lo mismo que el hecho desde el punto de vista penal sustantivo) ha llevado a

\footnotetext{
17 Esta materia se desarrollará más adelante.

18 Esta cuestión pone de relieve la importancia de los criterios normativos (enunciados) de la dogmática jurídica, a veces tan denostada por los prácticos. Vid. Larenz, K., Metodología de la Ciencia del Derecho. Ariel, Barcelona, 2001, pp. 177 y ss.

19 Salvo excepciones. En la doctrina chilena del último tiempo anota el problema, aunque no lo desarrolla, el profesor Cortez Matcovich (2006) pp. 274 y ss.
} 
que se plantee la infracción del deber de correlación de la sentencia porque ésta añade un detalle al relato fáctico de la sentencia, entendiendo la correlación de la sentencia como si se tratara de un deber de traslado o transliteración del relato de la acusación al relato de hechos probados de la sentencia, con lo cual se entiende que el relato fáctico de la sentencia no puede diferir en nada respecto del relato fáctico de la acusación. El riesgo de que esto se interprete de esta manera es evidente cuando se carece de un buen análisis teórico.

La nueva jurisprudencia ya ha tenido que pronunciarse al respecto y una parte de ella ha incurrido en este error al concebir la correlación con el hecho como una cuestión de coincidencia absoluta del relato fáctico ${ }^{20}$. Así se puede observar en el caso de la SCA de La Serena de 11 de diciembre de 2001, Rol Corte n. 133, en la cual se valora como una modificación fáctica que infringe el deber de correlación que la sentencia recurrida haya añadido al relato fáctico de la acusación un extremo que sólo se limitaba a especificar la forma en que se había concretado en el caso el robo con intimidación. En efecto, la acusación especificaba la comisión de un robo con intimidación en su relato fáctico y de ese mismo relato se desprendía que esa intimidación se había ejercido con el uso de una pistola de fantasía, sin embargo, no establecía expresamente que esa intimidación había consistido en que el acusado había apuntado con su pistola de fantasía a la cabeza de la víctima. Este extremo añadido por la sentencia -que el acusado apuntara

\begin{abstract}
Aunque hay otra jurisprudencia que viene sosteniendo lo contrario, pues hemos podido constatar que hay una corriente jurisprudencial que parece entender la correlación y la identidad del hecho que ésta supone de un modo más preciso. Se trata de ciertos fallos pronunciados por la primera sala del TJO de Antofagasta, y cuyo redactor es Dinko Franulic Cetinic, así en Sentencia de 20 de mayo de 2003, rol interno 30-2003; Sentencia de 10 de agosto de 2003, rol interno 70-2003, y Sentencia de 17 de septiembre de 2004, rol interno 93-2004. Así mismo la STJO de Rancagua, de 18 de noviembre de 2004, rol interno 67-2004, BDLN; STJO de Rancagua, de 18 de junio de 2005, rol interno 60-2005, BDLN; STJO de Iquique, de 10 de febrero de 2005, rol interno 2932004, BDLN; STJO de Arica, de 20 de septiembre de 2005, rol interno 53-2005, BDLN, y STJO de Santiago $\left(7^{\circ}\right)$, de 18 de enero de 2006, rol interno 3-2005, BDLN.

También SCA de Copiapó, de 23 de abril de 2004, rol 2-2004, que acierta al rechazar que modificaciones accesorias puedan suponer la infracción del deber de correlación; y SCA de Copiapó, de 24 de septiembre de 2007, rol 128-2007, BDLN. En el mismo sentido la SCA de Temuco, de 13 de octubre de 2003, rol 323-2003; SCA de Santiago, de 29 de marzo de 2006, rol 232-2006, BDLN, y SCA de Santiago, de 3 de agosto de 2007, rol 1121-2007, BDLN.

Así mismo hay jurisprudencia de la Corte de Apelaciones de Concepción que ha resuelto en determinados casos con acierto, pero sin proceder bajo criterios estrictamente técnicos para el hecho procesal y su eventual alteración. Vid. al respecto a Cortez Matcovich (2006) pp. 274 y ss. Últimamente puede consultarse SCA de Concepción, de 24 de septiembre de 2007, rol 416-2007, BDLN; SCA de Concepción, de 6 de diciembre de 2007, rol 586-2007, BDLN; SCA de Concepción, de 14 de diciembre de 2007, rol 601-2007, BDLN. Por último, la Corte Suprema ha dado ciertas soluciones correctas aunque sin explicar de manera precisa los criterios técnicos por los cuales llega a dichas soluciones. Vid. SCS de 23 de septiembre de 2005, rol 3297-2005, BDLN, en la cual se mantiene que el deber de correlación no se rompe con la modificación en sentencia de hechos o circunstancias accidentales, que para la Corte serían aquellas penalmente irrelevantes. Por tal motivo rechaza la infracción del deber de correlación.
\end{abstract}


Deber de congruencia (rectius, correlación) de la sentencia penal y objeto del proceso:

un problema no resuelto en la ley e insoluble para la jurisprudencia chilena

a la cabeza de la víctima- fue el motivo por el cual la Corte estimó el recurso de nulidad y anuló la sentencia por infracción del deber de correlación ${ }^{21}$.

Todavía más equivocada ha sido la decisión de otro recurso de nulidad por infracción de la correlación de la sentencia, en la que se condena a un sujeto por «violación reiterada» de una menor. La Corte de Apelaciones de La Serena, en Sentencia de 8 de abril de 2005, Rol Corte n. 57, estimó que había infracción del deber de correlación porque la sentencia impugnada modificó el espacio físico donde habían ocurrido los accesos carnales. La acusación afirmaba que ello había sucedido en el dormitorio del menor, mientras que la sentencia estableció que los hechos acaecieron en la cocina ${ }^{22}$.

Inapropiada asimismo es la solución dada por la SCA de La Serena, de 30 de marzo de 2005, Rol Corte n. 50, la cual también versa sobre la falta de correlación de una sentencia por delito de violación. En este caso se modificó el día preciso en que habría acontecido la violación y eso bastó para considerar que la sentencia excedía el contenido de la acusación ${ }^{23-24}$.

21 No han incurrido en este tipo de errores otras sentencias que, ante situaciones en que el juzgador añade una mayor especificación de la conducta formulada en acusación, pero que no llegan a alterar la esencialidad de la misma, han expresado que con ello no se rompe el deber de correlación. Vid por ejemplo la SCA de Santiago, de 29 de marzo de 2006, rol 232-2006, BDLN, en la cual se establece que la acusación de robo con intimidación con arma de fuego no fue modificada en su esencia por la precisión añadida en la sentencia de que el arma de fuego era de fogueo. Dicha circunstancia no tenía, se dijo, relevancia penal y por lo tanto era inocua a efectos de correlación.

Una segunda situación se presenta en STJO de Santiago ( $\left.7^{\circ}\right)$, de 18 de enero de 2006, rol interno 3-2005, en la que la sentencia modifica la cuantía de lo sustraído en el robo por el cual se formula la acusación. La cuantía según la prueba practicada en el juicio era superior a la que se sostenía en la acusación. Se dijo por el mismo tribunal que el hecho de la cuantía modificado no lesionaba el deber de correlación, ya que la cuantía era penalmente irrelevante en el robo con intimidación.

22 La posición contraria correcta ha sido sostenida últimamente en SCA de Santiago, de 3 de agosto de 2007, rol 1121-2007, BDLN, en la cual se establece que modificaciones espaciales que no afectan el derecho de defensa son irrelevantes a efectos de determinar el deber de correlación.

23 Éstas han sido Sentencias de Corte de Apelaciones, pero también ha habido fallos de instancia que cometen errores semejantes al interpretar el deber de correlación. Vid. Sentencia TJO de Antofagasta, de 16 de noviembre de 2002, rol interno 44-2002; Sentencia TJO de Copiapó, de 23 de diciembre de 2003, rol interno 66-2003; Sentencia TJO de Antofagasta, de 15 de septiembre de 2004, rol interno 106-2004.

24 En todos estos casos ni siquiera se puede decir que el tribunal ha aplicado un concepto natural de hecho, definido por criterios espacio-temporales, pues las mismas resoluciones citadas nada dicen al respecto. Sencillamente se limitan a considerar que el hecho no puede ser modificado, con lo cual se da a entender que esa invariabilidad implica lo que decíamos supra: la transliteración del relato de la acusación a la sentencia. Cuesta imaginar una concepción más extrema del hecho procesal (y más peregrina).

Afortunadamente no todas las Cortes de Chile piensan igual. Por ejemplo, la SCA de Copiapó de 23 de abril de 2004, rol 2-2004, ha establecido que un cambio sobre el día preciso en que suceden los hechos no afecta el deber de correlación, pues una modificación a este respecto no alcanza para entenderlo alterado. En el mismo sentido la SCA de Santiago, de 4 de julio de 2007, rol 1308, BDLN. También la STJO de Cauquenes, de 9 de noviembre de 2005, rol interno 22-2005, BDLN. 
Últimamente con una orientación parecida hemos encontrado la STJO de Santiago $\left(1^{\circ}\right)$, de 4 de abril de 2006, rit 15-2006. Se trata de un caso de tráfico de estupefacientes en que se sostiene que el acusado fue sorprendido y detenido con la droga cuando ingresaba al país en un vuelo aéreo de una compañía de aviación internacional el día 24 de septiembre de 2005. Resultó, sin embargo, que en realidad se le detuvo cuando iba saliendo del país con la droga, y el día de ingreso no había sido el 24, sino el día 23 de septiembre. Estas alteraciones al relato bastaron para que el TJOP considerara que el hecho que resultaba de la prueba era distinto del que formulaba la acusación, y por dicha razón decidiera absolver.

Es claro que en todos estos casos si se hubiere aplicado un concepto técnico de hecho se habría llegado a la solución contraria: la no infracción del deber de correlación.

Por ultimo, corresponde consignar que la carencia de un concepto adecuado de hecho también puede conducir al problema contrario, es decir, a no estimar infracciones al deber de correlación en casos en que ésta es evidente. Caso típico aquél en que detrás de una aparente modificación de la calificación jurídica del hecho se esconde una modificación fáctica sustancial.

Como se ve, estos son los problemas en el modelo chileno, justamente a causa de no tener claro que el objeto del proceso es el hecho y qué ha de entenderse precisamente lo que sea este.

Últimamente se ha producido una jurisprudencia de signo contrario a la expuesta, que viene a corregir parcialmente el problema consignado, pero que ha generado paralelamente otro nuevo a raíz de una concepción parcial e imprecisa del objeto del proceso y del deber de correlación y de los poderes de enjuiciamiento en relación con el objeto del debate.

La nueva corriente jurisprudencial sostiene esencialmente que el deber de correlación de la sentencia con la acusación viene referido al hecho punible que se atribuye al acusado, individualizado en su núcleo esencial (aunque no dice lo que es esto). Otras veces habla directamente de los hechos esenciales o sustanciales (en oposición a los accidentales o accesorios). Más allá del uso técnico preciso de las expresiones utilizadas la jurisprudencia adheriría a una suerte de teoría normativa del hecho que la jurisprudencia chilena, sin muchos argumentos, entiende basada en la trascendencia jurídico-penal de los mismos, de modo que sería relevante todo elemento fáctico que produce un efecto jurídico-penal e irrelevante a fines de correlación todo aquel que no produce dicho efecto. Concluye entonces que son irrelevantes todos los elementos espacio-temporales y los referidos a la forma de comisión concreta, los cuales pueden ser modificados o introducidos por el juez sin que ello importe infracción del deber de correlación. Aún cuando se trata de una visión más fina que la precedente resulta de todos modos inexacta y por ello generará dos órdenes de problemas.

Primero, nos referimos a la afirmación central de que el núcleo esencial del hecho comprende a todos los hechos con trascendencia jurídico-penal, de modo que son estos los que 
Deber de congruencia (rectius, correlación) de la sentencia penal y objeto del proceso:

un problema no resuelto en la ley e insoluble para la jurisprudencia chilena

determinan el objeto del proceso y la correlación de la sentencia. Esta afirmación es incorrecta y ello se puede demostrar con un ejercicio mínimo de lógica jurídica, como es que si -al contrariofuera cierta, sería prácticamente imposible sostener la posibilidad de un cambio de calificación jurídica en sentencia en cualquiera de sus aspectos, pues cualquiera modificación de ésta por mínima que sea, en la inmensa mayoría de los casos, tiene un soporte fáctico que correlativamente ha sido modificado y que justamente justifica la modificación de la calificación jurídica. Lo dicho debe ser la forma de entender lo que dispone el art. $341 \mathrm{CPP}$ que establece que «no se podrá condenar por hechos o circunstancias no contenidos en ella [la acusación]», pero que al mismo tiempo añade «el tribunal podrá dar al hecho una calificación jurídica distinta de aquella contenida en la acusación o apreciar la concurrencia de causales modificatorias agravantes de la responsabilidad penal no incluidas en ella, siempre que hubiere advertido a los intervinientes durante la audiencia».

Piénsese que de ser correcta la afirmación simplista de la jurisprudencia de que el núcleo esencial (o los hechos esenciales son) abarca a todo hecho con relevancia jurídico-penal sería imposible modificar en ninguna parte el contenido fáctico con trascendencia jurídico-penal de la acusación y por ese motivo sería inmodificable el aspecto subjetivo del hecho que permite pasar del título doloso al culposo o viceversa, o sería imposible pasar de un tipo base al tipo agravado, o pasar de un tipo a otro que se hallen en relación de homogeneidad, o estimar o desestimar en sentencia una circunstancia modificativa de responsabilidad no alegada por las partes, todas modificaciones de calificación jurídica, como se ha dicho, que suelen basarse en modificaciones fácticas introducidas en la sentencia, puesto que sólo de manera excepcional se sostienen en puras consideraciones jurídicas de Derecho a partir de hechos introducidos y alegados por las partes, como sería el caso que introducido y alegado un hecho se haga una incorrecta alegación de la consecuencia jurídico-penal: este supuesto excepcional equivaldría a la modificación de la calificación introducida en la sentencia como resultado del error o ignorancia del acusador sobre ese punto.

Por otra parte, y en segundo lugar, una concepción sobre el hecho como la sostenida por la jurisprudencia, en la que se señale que los hechos accesorios pueden ser modificados o introducidos en la sentencia sin más, desconoce no sólo la posible relevancia jurídico-penal de los mismos antes anotados, sino que además -incluso en caso de irrelevancia jurídico-penal de un elemento accesorio espacial, temporal o referido a la concreta forma de comisión delictivala relevancia que éstos pueden tener con relación al derecho de defensa en cuanto pueden modificar los términos del debate o afectar la eficacia de las alegaciones fáctico-jurídicas realizadas por las partes, de modo tal que su introducción, aun cuando no modifiquen el objeto del proceso y no se refiera stricto sensu al deber de correlación, pueden tener relación con el objeto del debate y con el derecho de defensa en los términos señalados. Por eso vale la pena distinguir con precisión, justo lo que no está haciendo la última jurisprudencia.

Lo que se viene diciendo sobre la jurisprudencia del último tiempo puede verse, entre 
otras, en la SCS de 24 de diciembre de 2007, rol 5415-2007, en la cual se afirma que en un delito de parricidio frustrado por envenenamiento son completamente irrelevantes la determinación del fármaco y de la dosis suministrado, de modo que el establecimiento en sentencia definitiva de estos elementos fácticos accesorios no constituye infracción al deber de congruencia. Con esto la sentencia justamente elude los problemas vinculados al objeto del debate y al derecho de defensa en juicio oral, pues resulta más que evidente que el conocimiento del fármaco y de la forma precisa de suministro y dosis en un envenenamiento resultan o pueden resultar datos fácticos relevantes con relación al objeto del debate. Es evidente que desde el punto de vista del objeto del debate y del derecho de defensa, en un delito de parricidio por envenenamiento, sí que importa el tipo de fármaco y la dosis utilizado para ocasionar la muerte ${ }^{25}$.

En la misma línea jurisprudencial criticada pueden consignarse la STJO de Cauquenes, de 9 de noviembre de 2005, rol 22-2005, en la que se descarta de plano la relevancia de las modificaciones del hecho en su ubicación o determinación temporal, y la STJO de San Felipe, de 6 de febrero de 2008, rol interno 63-2007, en la cual, a su turno, se desestima la importancia de la determinación espacial del hecho sin mayores motivaciones al respecto.

A propósito de esta cuestión conviene mencionar el dilema al que se ha debido enfrentar nuestra jurisprudencia a raíz de una regulación normativa imperfecta y lagunar en aspectos cruciales. Causa fundamental del problema referido es la imprevisión normativa sobre la necesidad de actualizar la acusación en el curso del juicio oral, especialmente al resultado probatorio y la necesidad correlativa de prever oportunidades procesales finales para la ampliación del debate y de prueba nueva. En nuestro sistema existe una sola oportunidad de acusación, situada antes de la práctica de la prueba. Dicha imprevisión que suponía (y supone) una fuerte preclusión acusatoria ex ante, previa a la práctica de la prueba, la jurisprudencia quiso -en una primera respuesta- corresponderla con una forma de vinculación extrema del juez a los hechos de la acusación que no podría ser alterada en absoluto (apenas sí disminuida). Posteriormente, ante las soluciones erróneas a que se llegaron con este criterio, se ha intentado otra solución, también insatisfactoria, que es la últimamente aplicada y que se quiere imponer, fundada en una «teoría normativa reduccionista del hecho» por la cual se pretende resolver el problema con una sola regla simplificadora que distinga entre hechos relevantes (sustanciales) e irrelevantes (accidentales), estableciendo que sólo los primeros importan a la correlación, y los otros, por irrelevantes, el juez pueda introducirlos sin más. Hemos señalado ya, de manera sinóptica, la doble imprecisión en que se incurre. Veremos ahora en detalle los diversos y complejos asuntos que se hallan incluidos en las cuestiones referidas.

25 Para un estudio completo del objeto del debate y las cuestiones vinculadas, y las diferencias que mantiene con el objeto del proceso vid. Del Río Ferretti (2007) pp. 58 y ss. 
Deber de congruencia (rectius, correlación) de la sentencia penal y objeto del proceso:

un problema no resuelto en la ley e insoluble para la jurisprudencia chilena

\section{CONFIGURACIÓN TÉCNICO PROCESAL DEL HECHO PROCESALMENTE RELEVANTE COMO OBJETO DEL PROCESO: LA CLAVE DEL DEBER DE CORRELACIÓN OBJETIVA}

Los ejemplos dados demuestran la necesidad de adentrarse en la configuración técnica del hecho, de su contenido e identidad como objeto procesal. En doctrina ha habido consenso teórico en que el objeto del proceso penal se identifica por el hecho en que se funda la pretensión procesal. Sin embargo, ese consenso inicial tiende a desaparecer cuando se trata de aclarar qué es el hecho procesalmente relevante, cuestión que es en definitiva lo fundamental para determinar precisamente en qué consiste la correlación objetiva que debe guardar la sentencia con el hecho de la acusación.

Para dimensionar la necesidad de tener claridad de lo que sea el hecho a efectos de objeto del proceso conviene consignar que aquello posee una primera repercusión que ya hemos puesto de manifiesto, cual es que permite precisar o determinar la amplitud y límites del asunto penal $\mathrm{y}$ de los poderes de resolución jurisdiccional del juez en cada caso concreto: es lo que hemos venido explicando bajo la denominación de deber de correlación. Pero junto con lo anterior hay que tener presente que el hecho conformador del objeto del proceso determina al mismo tiempo la amplitud del efecto excluyente o negativo de cosa juzgada (el ne bis in idem), así como la litis pendencia. Es decir, el objeto procesal (el hecho) es relevante además para la determinación de los efectos externos al proceso concreto en que se ha resuelto el asunto, como de manera categórica se encarga de establecer en nuestro Derecho el art. 1 inciso $2^{\circ} \mathrm{CPP}$, a menos que se distingan dos conceptos distintos de objeto del proceso, uno para efectos de correlación (res iudicanda) y otro para la determinación de la cosa juzgada (res iudicata) como hace la doctrina italiana ${ }^{26}$.

Por lo expuesto es que es menester configurar una teoría del hecho procesal, teniendo en cuenta ambas cuestiones. Debe haber un régimen armónico y coherente. Nótese que si se predica un concepto súper exigente de hecho procesal, pensando que con ello se garantiza los derechos del imputado se puede en realidad estar cometiendo un error fundamental, pues aquello podría suponer un efecto excluyente (del ne bis in idem) muy limitado en su amplitud objetivo-subjetiva, al punto de que cualquier cambio fáctico insignificante introducido en la segunda acusación pueda dejarlo sin eficacia, puesto que habría que concluir de manera coherente con aquello de que cualquiera cambio o alteración también afecta la identidad del hecho a efectos de cosa juzgada: el hecho ya no sería el mismo, sino justamente uno distinto, no quedando, por lo tanto cubierto por la mencionada garantía (art. 1 inciso $2^{\circ} \mathrm{CPP}$ ). Esta es la razón por la cual al tratar 
del hecho configurador del objeto del proceso que nos servirá para determinar el deber de correlación habrá que estar a la vez pensando en las consecuencias que ello puede acarrear para la cosa juzgada y la litis pendencia. Salvo, dicho está, que concibamos conceptos diversos de hecho: uno para efectos de correlación muy exigente y completo y otro mucho más simple para el efecto excluyente de cosa juzgada, con el propósito de limitar, por una parte, al máximo al juez de la causa en sus poderes de decisión (en el pronunciamiento de la sentencia) y, por otra, asegurar a la vez el más amplio efecto excluyente de ese pronunciamiento. Así acontece en el modelo italiano del CPPi, que regula ambas situaciones con detalle y claridad técnica, lo cual hace una gran diferencia con nuestro CPP, que en este aspecto como en otros se caracteriza por la franca imprevisión normativa. Nuestro legislador no tuvo consciencia de la necesidad de regular estas cuestiones, ni prevé normativamente los complejos problemas que derivan de allí, hasta el momento insolubles en la práctica forense y en la doctrina. De ahí la grave dificultad interpretativa de llegar a la conclusión de que nuestro CPP quisiera introducir un sistema complejo de doble configuración del hecho, uno que podríamos denominar res iudicanda y otro para efectos de cosa juzgada, que podríamos denominar res iudicata. En efecto, una configuración doble del hecho requiere de la regulación de varios resguardos normativos referidos a la forma de ejercicio de los poderes de acusación y a la posibilidad de actualización y control sobre el contenido acusatorio, cuestiones que simplemente nuestro legislador ni tan siquiera esboza. Esta es la razón por la que -con la forma actual de nuestro modelo de proceso penal- esta posibilidad técnica debe ser descartada ${ }^{27}$.

En este trabajo nos limitaremos al estudio de las posiciones teóricas que se adaptan a la regulación prevista en el CPP. Éstas son aquellas que sostienen una posición unitaria del hecho y del objeto del proceso. Es decir, descartamos, por las razones dadas supra, una configuración doble del hecho y del objeto del proceso, el cual, sin embargo puede revestir interés de lege ferenda.

Dentro de las posiciones unitarias, la doctrina procesal ha considerado la cuestión del hecho (del objeto procesal) en su aplicación para la correlación y para la cosa juzgada (y litis pendencia). Por ello siempre se han propuesto teorías explicativas del hecho que dan un enfoque que aborda ambas cuestiones, con la finalidad de otorgar un régimen procesal completo y técnico. Hay dos posiciones en la dogmática que pretenden dar una respuesta unitaria y coherente al tema de la identificación del hecho desde un punto de vista procesal. Nos referimos a la teoría naturalista y a la teoría normativa.

27 Se profundiza en las razones técnicas para la doble configuración del hecho y del objeto procesal en el modelo italiano y las previsiones normativas que ello supone en Del Río Ferretti (2007) pp. 190 y ss. 
Deber de congruencia (rectius, correlación) de la sentencia penal y objeto del proceso:

un problema no resuelto en la ley e insoluble para la jurisprudencia chilena

A continuación haremos una exposición acabada de estas posiciones teóricas sobre el hecho del objeto del proceso con el fin de demostrar las importantes repercusiones técnicas implicadas en la materia. Explicaremos también nuestra posición crítica y las posibilidades de configuración del hecho en el sistema chileno.

\section{Teoría naturalista}

El proceso penal, según esta posición, necesita de un concepto del hecho naturalista para distinguir el «hecho por el que se procede» del «hecho punible» en el sentido de la ley penal: el hecho procesal está constituido por un acaecimiento o «trozo de vida» ${ }^{28}$ y no por un concreto tipo penal. La concepción naturalística considera que la identificación ha de hacerse con base en criterios puramente naturales, de los cuales habrá de surgir una unidad: la unidad de acción natural. Para ello se recurre a criterios históricos o naturales que permitan conseguir una cierta delimitación del hecho que sirva de medida con miras a conformar un objeto del proceso.

\subsection{Criterio espacio-temporal}

Como primer criterio se utilizó la determinación espacio-temporal, así el hecho procesalmente relevante sería un simple acaecer histórico dentro de sus límites espaciotemporales ${ }^{29-30}$. Es decir, para individualizar el hecho había que atender a criterios de determinación espacial y temporal del acaecimiento histórico, en consecuencia, a efectos de identificación del hecho había que preguntarse: ¿qué cosa, dónde y cuándo? El resultado de las respuestas a estas tres cuestiones era el objeto del proceso.

Esta teoría acierta en cuanto pone de relieve que el objeto del proceso es un factum y no un ius, y además demuestra que «el hecho punible en el sentido del Código penal (acción u omisión) no es el hecho punible objeto del proceso penal, que aquél varía según los distintos tipos penales, y éste solamente según las causas naturales que lo motivaron $»^{31}$, de manera que esta concepción permite distinguir el hecho penalmente relevante del hecho procesalmente relevante, porque como hemos señalado, el elemento individualizador de la acción es un hecho,

Gómez Orbaneja, E., Comentarios a la Ley de Enjuiciamiento Criminal, tomo I. Bosch, Barcelona, 1951, p. 296. Gutiérrez de Cabiedes, E., «La correlación entre acusación y sentencia», en Estudios de Derecho procesal. EUNSA, Pamplona, 1974, p. 523.

30 Dentro de la tradición italiana puede consultarse a La Rocca, M., Studi sul problema del «fatto» nel proceso penale. Eugenio Jovene, Nápoles, 1954, pp. 7-35 y 40-71. En España sustenta esta teoría Fenech Navarro, M., Derecho procesal penal, tomo I. Bosch, Barcelona, 1945a, pp. 418-419, y del mismo Derecho procesal penal, tomo III. Bosch, Barcelona, 1945b, pp. 318-319.

Gutiérrez de Cabiedes (1974) pp. 523-524. 
nunca un delito, razón por la cual el juez puede pasar de un delito a otro sin romper la identidad del objeto del proceso ${ }^{32}$.

En segundo lugar, la teoría naturalista permitiría discernir entre actos que forman parte de la unidad de acaecer natural, de cualquier otro acto del sujeto pasivo que no queda dentro de la identidad del hecho. Sin embargo, la realidad demuestra que esto no es así, y que justamente el principal problema de este criterio es que no permite distinguir acertadamente la unidad del hecho en ciertos casos.

GUTIÉRREZ DE CABIEDES ${ }^{33}$ plantea serias dudas acerca de esta segunda cuestión de la teoría naturalista, es decir, de la distinción entre actos que forman parte de la unidad natural $y$ aquellos otros que quedan fuera de esa unidad natural y que por tanto no caben dentro del «hecho». Su argumento central se basa en que el hecho histórico estaría compuesto de infinidad de menudos hechos que sólo pueden ser agrupados atendiendo a criterios jurídicos. Y pregunta «¿Cómo podría saberse dónde empieza y dónde acaba la historia procesal sin un criterio valorativo jurídico? ¿Cómo se acota ese trozo de vida del conjunto casi infinito de acontecimientos que componen el hecho sujeto a enjuiciamiento? ¿Cómo se separan, sin método estrictamente jurídico, los puramente accidentales de los trascendentes?» ${ }^{34}$.

Se sostiene, en consecuencia, que esta teoría no es suficiente por sí sola para dar respuesta a ciertas cuestiones que presentan dificultades en la determinación de la amplitud del objeto del proceso ${ }^{35}$. En efecto, en ciertos casos la pura referencia a criterios espaciales y temporales del hecho histórico se manifiestan ambiguos o imprecisos para la resolución de hipótesis cuya unidad no se delimita por estos criterios, así, por ejemplo, cuando el hecho no se contrae a un lapso determinado de tiempo, como sucede en el caso de lesiones de las que se derivan muchos meses después la muerte de la víctima ${ }^{36}$, o cuando el hecho histórico natural no puede servir de

32 Gómez Orbaneja (1951) p. 297. Coinciden en lo mismo Gutiérrez de Cabiedes (1974) p. 523, y Roxin, C., Derecho procesal penal. Editores del Puerto, Buenos Aires, 2000 (traducción de Córdoba y Pastor), pp. 160165.

33 Gutiérrez de Cabiedes (1974) p. 524.

$34 \quad$ Ibid. cit. supra.

35 La jurisprudencia chilena no realiza consideraciones técnicas sobre la identidad del hecho, aunque de manera intuitiva ha tenido que resolver sobre la cuestión, aplicando, a veces, criterios espacio-temporales y en otras señalando que estos no sirven a ese fin de identificación del hecho. Como ejemplos de sentencias que aplican los criterios espacio-temporales se pueden citar, entre otras, la STJO de Santiago ( ${ }^{\text {a }}$ Sala), de 4 de abril de 2006, rol interno 15-2006; SCA de Serena, de 30 de marzo de 2005, rol 50, y SCA de Serena, de 8 de abril de 2005 , rol 57. Por la posición que rechaza la aplicación de estos criterios, se puede citar la SCA de Copiapó, de 23 de abril de 2004, rol 2-2004; SCA de Santiago, de 4 de julio de 2007, rol 1308-2007, BDLN, y SCA de Santiago, de 3 de agosto de 2007, rol 1121-2007, BDLN.

36 Caso citado por Gómez Orbaneja (1951) pp. 301-302, y Asencio Mellado, J.M., Principio acusatorio y derecho de defensa en el proceso penal. Trivium, Madrid, 1991, p. 75. Y en sentido análogo Gutiérrez de Cabiedes (1974) pp. 524-525, agrega más adelante: «Por otro lado, hechos históricos y naturalmente diversos se presentan 
Deber de congruencia (rectius, correlación) de la sentencia penal y objeto del proceso:

un problema no resuelto en la ley e insoluble para la jurisprudencia chilena

referente, como es el caso de distintas formas de participación, como son la autoría y la complicidad, las que desde un punto de vista natural son hechos distintos, pero que desde una perspectiva procesal (para la teoría normativa) constituirían un mismo hecho ${ }^{37}$, o también el caso de distintos grados de ejecución del delito, como son la consumación, la tentativa y frustración $^{38}$ en que la coincidencia de los hechos desde un punto de vista natural no existe o es parcial, mientras que para la teoría normativa el hecho procesal sería el mismo. Por último, pueden presentarse otros casos que hagan indispensable considerar criterios jurídico-penales, como en supuestos de delito continuado y concurso ideal ${ }^{39}$, según se verá más adelante.

\subsection{Criterio subjetivo (volitivo)}

Paralelamente ${ }^{40}$ se ha propuesto un segundo criterio dentro de la teoría naturalista que consiste en la referencia a la voluntad del autor. Es decir, el elemento que permitiría discernir la unidad natural del hecho es la constatación de que el agente (sujeto pasivo del proceso) persigue un fin particular que se proyecta en una conducta material ${ }^{41}$. La identidad del hecho, por lo tanto, depende en esta teoría de la invariabilidad del elemento volitivo ${ }^{42}$.

También este criterio es criticado por su inseguridad e insuficiencia ${ }^{43}$ para distinguir en

a los efectos del proceso penal como una unidad. No puede dudarse que históricamente el hecho de la agresión homicida es absolutamente distinto de la muerte sobrevenida días o incluso meses después. ¿Se puede decir a efectos procesales, en el caso anterior, que la acusación por homicidio frustrado o por lesiones, es distinta a la acción por homicidio consumado en (sic) base al posterior óbito? Naturalísticamente, es claro que son dos hechos temporal y espacialmente diversos, pero procesalmente no (...)».

37 Vid. Gutiérrez de Cabiedes (1974) p. 525, que dice: «En los casos de distintos grados de participación y de desarrollo del delito, los ejemplos son mucho más convincentes. Qué duda cabe que el hecho de la autoría históricamente es por completo distinto al hecho del encubrimiento; precisamente éste comienza según el artículo 17 de nuestro Código penal donde termina aquél. Ahora bien, la acusación como autor no empece a la condena como encubridor y viceversa. Lo mismo puede decirse de la tentativa y la frustración».

$38 \quad$ Ibid. cit. supra.

39 Tanto Gómez Orbaneja (1951) pp. 307-313, como Gutiérrez de Cabiedes (1974) p. 530, evidencian la insuficiencia de la teoría naturalista en estos casos. Roxin (2000) pp. 160-163, sostiene que el concurso ideal debe ser ser tratado como unidad de hecho a efectos procesales.

40 Vid. las explicaciones de Bettiol, G., «La correlazione fra accusa e sentenza nel processo penale», en Scritti giuridici, tomo I, Cedam, Padua, 1966, pp. 252-253, y de Gutiérrez de Cabiedes (1974) p. 525.

41 Vid. La Rocca (1954) pp. 7-35 y 40-71, quien hace una presentación completa de la importancia del elemento volitivo en la individualización del hecho, aunque el autor considera que la individualización es fundamentalmente histórica, no deja de reconocerle importancia.

42 Adhieren a esta concepción Berner, Der Grundsatz des ne bis in idem im Strafprozess. Leipzig, 1891 p. 64; Eichhorn, «Non bis in idem und das Reichgericht», en Gerischstaal, Band 38, pp. 416-417; LANG, Die Rechstshängigkeit im Strafverfahren, Leipzig, 1910, p. 43; Florián, E., Parte generale del diritto penale, Milán, 1932, p. 729; Vid. también la explicación de La Rocca (1954) p. 42, que si bien no adhiere a esta teoría.

43 La doctrina moderna italiana retoma este elemento volitivo: elemento subjetivo de la fattispecie, junto a otros elementos, para reformular la doctrina del hecho a efectos de imputación fáctica y correlación, más acorde con un sistema acusatorio. 
forma adecuada ciertas hipótesis, así, por ejemplo, el problema que se presenta en la distinción entre dolo y culpa, ya que la pura afirmación de que en un delito concurre culpa y no dolo (modificación de la voluntad del agente), comportaría la modificación del hecho. Bien es verdad que algunos autores han intentado evitar esta consecuencia lógica señalando que entre culpa y dolo hay una comunidad de voluntad interna con distinta gradación ${ }^{44}$, pero si ello es efectivo entonces habría que concluir que el elemento volitivo es ineficaz e irrelevante a efectos de identificación del hecho.

En segundo lugar, se ha criticado la referencia a la voluntad del autor en la medida que un criterio puramente volitivo de la acción con las miras puestas en un fin específico, nos puede llevar a establecer objetos procesales cada vez que concurra una voluntad específica dirigida a un fin, dando lugar a un solo objeto procesal, cuando en realidad existan varios (concurso material o medial). Esta crítica señala que de utilizarse el criterio de la voluntad, varios hechos específicos dentro de una unidad de voluntad delictiva generaría un objeto procesal único, lo que por supuesto parece del todo inconveniente ${ }^{45}$.

Son estas las principales objeciones que se le formulan al criterio volitivo. La doctrina que hace estas críticas, pretende, mediante una valoración normativa del hecho, dar una respuesta a los problemas de la identificación del objeto del proceso que se derivan de la sola aplicación de los criterios naturalistas del hecho.

\section{Visión normativa del hecho}

Las concepciones normativas del hecho pretenden contestar a la cuestión de la identidad del hecho desde una valoración jurídico-penal del mismo, puesto que, como hemos visto, consideran incorrecta la pura utilización de los criterios naturales, estimando necesario adoptar una visión de Derecho penal sustantivo con el objeto de poder disponer de un criterio que les permita identificar el hecho y medir su invariabilidad (o identidad) en todos los casos, y sobre todo en aquellos en que los criterios naturales se mostraron inútiles.

Vid. Gómez Orbaneja (1951) p. 298; Gutiérrez de Cabiedes (1974) pp. 525-526. También Asencio Mellado (1991) pp. 74-75.

$45 \quad$ Asencio Mellado (1991) p. 74, dice «Sin embargo este dato de la voluntad, que coincide con el rasgo volitivo típico del Derecho penal material, ha sido desterrado en sede procesal por muy diversas razones. Así, por ejemplo, se dice que en atención al mismo podría configurarse como un solo hecho y constituir un objeto procesal independiente toda acción realizada con las miras puestas en un fin específico, tales como el robo del arma para cometer el asesinato; el robo de la cartera con cuyo producto comprar el billete del autobús para acudir al lugar donde se cometió la violación, etc.; así como los múltiples robos, estafas, etc. llevados a cabo durante años para conseguir el enriquecimiento personal». 
Deber de congruencia (rectius, correlación) de la sentencia penal y objeto del proceso:

un problema no resuelto en la ley e insoluble para la jurisprudencia chilena

Esta teoría ${ }^{46}$ busca en el concepto jurídico-sustantivo de hecho (hecho penal) uno o más elementos que sirvan a efectos de la determinación procesal del mismo ${ }^{47}$, intentando hacer una valoración jurídico penal, pero sin confundir el hecho procesal con un preciso hecho penal ${ }^{48} \mathrm{o}$ delito. El hecho procesal sigue siendo un factum con individualidad propia, pero se ha de tener en cuenta que este factum lo es dentro de un asunto penal ${ }^{49}$, de una relación de Derecho procesal penal y penal, manifestado en la imputación de un hecho supuestamente ilícito a una persona que eventualmente habrá de soportar una consecuencia penal. Por eso SCHMIDT ${ }^{50}$ dice que «El punto de vista decisivo desde el cual se mira el objeto del proceso es el de la «causa penal» (...) Un asunto procesal representa una «causa penal» siempre que el juez, para la valoración de la acción que forma el núcleo del asunto haya tomado su criterio de los preceptos penales, es decir, de los preceptos jurídicos en los cuales a una acción como tipo se vincula una pena como consecuencia jurídica.»

La realidad de la subsunción de una acción y de un resultado en una norma penal impone la necesidad de tener en cuenta ciertos elementos conformadores de ésta. Piénsese, por ejemplo, en los casos que ya mencionamos: las lesiones de las que se derivan muchos meses después la

Es Von Kries, en la doctrina alemana, quien se comienza a apartar de la teoría naturalista, y Beling el primero en sostener que sin una especial visión jurídico penal del hecho es imposible identificarlo procesalmente. Modernamente, aunque con matices, Schmidt, E., Los fundamentos teóricos y constitucionales del Derecho procesal penal. Depalma, Buenos Aires, 1957 (traducción de Núñez), pp. 35-43; Baumann, J., Derecho procesal penal. Conceptos fundamentales y principios procesales. Depalma, Buenos Aires, 1989 (traducción de Finzi), pp. 267-294, y Roxin (2000) pp. 160-163 y 415-417. La doctrina española sigue muy de cerca a la doctrina alemana a partir de las explicaciones en este sentido de Gómez Orbaneja (1951) p. 301, y Gutiérrez de Cabiedes (1974) pp. 526-529. Vid. Cortés Domínguez, V., La cosa juzgada penal. Publicaciones del Real Colegio de España, Bolonia, 1975, pp. 60 y ss; Vázquez Sotelo, J.L., «El principio acusatorio y su reflejo en el proceso penal español», en Revista Jurídica de Catalunya, № 2, 1984, pp. 126-128; Verger Grau, J., La defensa del imputado y el principio acusatorio. Bosch, Barcelona, 1994, pp. 109-113; Asencio Mellado (1991) pp. 76-80; Pérez Morales, M.G., Correlación entre acusación y sentencia en el proceso ordinario. Doctrina y jurisprudencia. Comares, Granada, 2002, pp. 25-26; Cucarella Galiana, L., La correlación de la sentencia con la acusación y la defensa. Aranzadi, Cizur Menor, 2003, pp. 129-136.

$47 \quad$ Vid. Gómez Orbaneja (1951) p. 301; Asencio Mellado (1991) p. 76.

48 Una explicación sobre el concepto naturalista y normativo del hecho penal (que no procesal) puede consultarse en Gössel, K.H., «Acerca del normativismo y del naturalismo en la teoría de la acción», en Derecho penal contemporáneo. Revista internacional, 21, octubre-diciembre de 2007, pp. 153-171.

49 En términos generales la doctrina suele afirmar que el proceso penal requiere de una visión normativa del hecho, es decir, jurídico-penal-sustantivo, ya que a través del proceso el hecho procesalmente relevante no es el hecho desnudo, sino aquel valorado desde un punto de vista jurídico. Se afirma que desde el inicio del proceso el hecho es valorado desde un punto de vista penal sustantivo, así en el trámite de admisión de la querella se requiere de una valoración penal sustantiva del hecho, luego en el sobreseimiento o en la apertura del juicio oral también existe una valoración penal sustantiva del mismo. Vid. en general Schmidt (1957) pp. 35-43; Asencio Mellado (1991) p. 73; Verger Grau (1994) pp. 109-112; Cucarella Galiana (2003) pp. 128-129. Roxin (2000) pp. 160 y ss, señala que debe preferirse una combinación de criterios fácticos y normativos para la determinación del hecho procesalmente relevante. 
muerte de la víctima, o los casos de distinta forma de participación o de distinto grado de perfección, así como también los casos de delito continuado y concurso ideal, en los cuales los criterios espacio-temporal y volitivo se manifiestan claramente insuficientes.

En estos casos se hallan involucradas valoraciones de naturaleza penal sustantivas, que se encuentran resueltas por la ley penal previas definiciones dogmático-penales, razón por la cual es imprescindible hacer valoraciones normativo-penales del hecho o del objeto del proceso que superan los criterios naturalistas señalados ${ }^{51}$.

\subsection{Criterio del objeto normativo definido por la acción típica}

Este criterio fundamental para averiguar la identidad del hecho sostiene que lo importante para la permanencia inalterable de éste no es que permanezca invariable su unidad material sino la subsistencia de su objeto normativo ${ }^{52}$. El núcleo central de esta teoría considera que el «objeto normativo es un elemento común a varios tipos penales que viene a constituir la esencia de todos ellos. En el hecho punible, el elemento principal es ese elemento normativo que hace que aunque los elementos accidentales cambien, el hecho procesalmente sea el mismo. El juez, por deber de oficio, provocado por la legalidad y oficialidad del proceso penal, tiene la obligación de buscar y mantenerse dentro del objeto normativo, pero no se encuentra ligado por los elementos accidentales del conjunto ${ }^{53}$.

Luego, los elementos accidentales del hecho de la acusación pueden ser modificados o introducidos o eliminados por el órgano jurisdiccional y ello no supone un cambio de objeto ${ }^{54}$.

$51 \quad$ Asencio Mellado (1991) pp. 76-77, dice que «en los supuestos de unidad legal material, como lo es el concurso ideal, que históricamente comprende hechos distintos pero que se reúne en uno solo por la voluntad exclusiva de la Ley; así, sostiene BERTEL, el Código Penal, en atención a la importancia misma del bien jurídico infringido, concluye soluciones diferenciadas y establece unidades o pluralidades delictivas ante supuestos de acciones similares de modo que, por ejemplo, quien en un solo acto roba a varias personas comete un único delito de robo, mientras que el que coloca una bomba y mata simultáneamente a varias personas, realiza tantos delitos de asesinato como sujetos hayan perdido la vida».

«Es necesario, pues encontrar una solución en sede normativa que ofrezca los elementos útiles al fin de identificación del hecho que signifiquen un criterio seguro y, sobre todo, con vocación general, que permitan concretar el dato de la esencialidad siempre invariable como parámetro utilizable en orden a la comparación entre el hecho acusado y aquel que es objeto de la condena».

52 Esta es la teoría predominante en la doctrina española desde que Gómez Colomer (1951) pp. 302 y ss, adhiriera sin reservas a ella. Luego le han seguido con matices Gutiérrez de Cabiedes (1974) pp. 526-529; Cortés Domínguez (1975) pp. 60 y ss; Vázquez Sotelo (1984) pp. 126-128; Verger Grau (1994) pp. 109-113; Asencio Mellado (1991) pp. 76-80; Pérez Morales (2002) pp. 25-26; Cucarella Galiana (2003) pp. 129-136.

53 Gutiérrez de Cabiedes (1974) p. 527. También es el criterio de Schmidt (1957) pp. 35-43. Una buena exposición de la teoría normativa en sus distintas manifestaciones alemanas e italianas puede encontrarse en La Rocca (1954) pp. 42-50.

$54 \quad$ Vid. Roxin (2000) pp. 160-161. 
Deber de congruencia (rectius, correlación) de la sentencia penal y objeto del proceso:

un problema no resuelto en la ley e insoluble para la jurisprudencia chilena

Por otra parte, este concepto normativo permite distinguir un hecho punible de otros extraños y distintos. El criterio es que aquellos hechos que no estén abrazados por el núcleo básico determinado por el elemento común de un grupo de delitos forman un objeto procesal distinto, de modo que el juzgador no puede enjuiciarlos sin una previa acusación. Con todo, estos hechos pueden haber sido objeto de acusación con otros hechos distintos y ser juzgados en el mismo juicio oral en virtud de la aplicación de las normas de conexión, sobre la base de un concurso real de delitos ${ }^{55}$, o simplemente por la acumulación de objetos ${ }^{56}$.

Ahora bien, el objeto normativo es un concepto, hasta aquí, definido en un sentido puramente formal, sin un contenido determinado que nos permita concretarlo. Para darle este contenido que reclamamos se ha recurrido al concepto penal de la acción típica.

El concepto de acción se basa en la consideración de los actos típicos de la ejecución descritos por la ley penal a efectos de individualizar el hecho procesal. Es decir, se estima que existe identidad normativa del hecho de la acusación con el de la sentencia cuando, al menos, se da una coincidencia parcial entre el hecho de la acusación y el supuesto fáctico típico de la norma penal aplicada en la sentencia, o lo que es lo mismo, existe identidad normativa cuando se da una identidad parcial del hecho como actividad del Tatbestand de la norma jurídica invocada por la acusación, y aquella constitutiva de la norma utilizada por la sentencia como base para la condena o absolución ${ }^{57}$.

Es evidente que si se predica la exigencia de la coincidencia parcial de la acción típica de la acusación y la que se estima en la sentencia, se resuelven aquellos problemas que se suscitaban con la teoría naturalista respecto de aquellos hechos que no se contraían a un lapso de tiempo (lesiones que devienen en muerte), tanto como aquellos supuestos en que el hecho está compuesto por diversidad de acciones naturales (distintos grados de perfección del delito, delito continuado), pues en dichos casos basta con que haya una coincidencia parcial de la acción, lo cual se cumple. Pero al mismo tiempo es menester reconocer que al establecer un criterio elástico y, por qué no decirlo, poco exigente de hecho (la sola coincidencia parcial de la acción típica),

Vid. Gutiérrez de Cabiedes (1974) p. 527, sobre la teoría normativa concluye «De esta doctrina puede desprenderse una proposición negativa: no son objeto del proceso penal aquellos hechos que no están abrazados por aquél núcleo básico mencionado, por más que estén ligados como medio a fin con los hechos que forman el objeto (v.gr., el robo del veneno para el asesinato posterior). Estos hechos pueden venir sometidos al juez del proceso principal atendiendo a las normas de conexión (...), pero provocarán una acumulación de objetos procesales y un verdadero concurso real de delitos».

56 Vid. art. 274 en relación con art. 185, ambos del CPP.

57 Asencio Mellado (1991) pp. 77-78. 
ello significa mayores poderes para el juez a la hora de apreciar e introducir modificaciones al hecho imputado por el acusador ${ }^{58}$.

Con esta forma de entender la identidad del hecho, quedan fuera de esa identidad (sustancial) y devienen irrelevantes (accidentales) una serie de elementos de hecho que forman parte de la imputación fáctica de la acusación, dando al juez unos márgenes amplios para retocar o modificar esas partes de la imputación. En efecto, en esta teoría son considerados elementos fácticos irrelevantes en la identificación del hecho los elementos de tiempo y de lugar concretos, es decir, aquellos elementos fácticos que individualizan históricamente el hecho imputado en la acusación. Pero además también quedan fuera del hecho procesalmente relevante aquellos elementos fácticos que forman parte del hecho penalmente relevante, como el nexo causal y el resultado, o que no siendo parte del hecho producen igualmente efectos jurídico-penales, tal como el elemento fáctico-subjetivo o calificante. Bajo el criterio de la coincidencia parcial de la acción típica, tanto los primeros como los segundos elementos pueden ser modificados en la sentencia sin alteración sustancial del hecho objeto del proceso ${ }^{59}$.

\subsection{Criterio del bien jurídico}

El criterio de la acción típica ha sido criticado por ser insuficiente. Se dice, en general, que no es posible imaginar una actividad humana sin un resultado y por tanto ese resultado debe ser tenido en cuenta con vista a la identificación del hecho: el hecho necesita la referencia del resultado para ser más precisamente determinado, al menos desde un punto de vista jurídicopenal $^{60}$, lo cual no sucede con la sola aplicación del criterio de la acción. Los actos de ejecución

Esta característica de la concepción normativa de la acción típica es la que en definitiva, como se verá, provoca su rechazo por una parte de las doctrinas modernas.

59 Ésta ha sido la preocupación constante de la doctrina italiana desde Bettiol, Manzini y La Rocca en adelante, que la ha llevado a rechazar la doctrina del objeto normativo, proponiendo otras formas de individualizar el hecho. Vid. Bettiol (1966) pp. 239 y ss; Manzini, V., Trattato di procedura penale italiana, volumen II, Fratelli Bocca editori, Milán, Turín y Roma, 1914, pp. 429-430, y del mismo Tratado de Derecho procesal penal, volumen IV, EJEA, Buenos Aires, 1953 (traducción de Sentís Melendo y Ayerra Redín), pp. 50-62; Cordero, F., «Considerazioni sul principio d'identità del fatto», en Rivista italiana di diritto e procedura penale, 1958, pp. 939-941, y del mismo Procedura penale, sexta edición. Giuffrè, Milán, 2001, pp. 452-455; Rafaraci, T., Le nuove contestazione nel processo penale, Giuffrè, Milán, 1996, pp. 1-25; Calamandrei, I., «Diversità del fatto e modifica dell'imputazione nel Codice di Procedura Penale del 1988», en Rivista di Diritto e Procedura Penale, 1996, pp. 643 y ss; Giannitti, P., «Rilievi sul «fatto» nel processo penale», en Rivista italiana di diritto e procedura penale, Giuffrè, Milán, 1999, pp. 409-411; Giarda, A., y Spangher, G., Codice di procedura penale. Comentario, segunda edición. IPSOA, Milán, 2001, pp. 1464-1468. En un trabajo específico sobre la culpa genérica y culpa específica, Castronuovo, D., «La contestazione del fatto colposo: discrazie tra formule prasseologiche d'imputazione e concezione teoriche della colpa», Cassazione penale, 12,2002 , pp. 3836 y ss.

60 Vid. Bettiol (1966) pp. 251 y 267 y ss. Para este autor la tesis normativa se construye sobre la base del caso del delito continuado, concebido éste como una unidad jurídica a los fines sustanciales, y no como una unidad jurídica a fin de mitigar la sanción penal, de manera que, por ejemplo, una acusación de hurto simple puede 
Deber de congruencia (rectius, correlación) de la sentencia penal y objeto del proceso:

un problema no resuelto en la ley e insoluble para la jurisprudencia chilena

típica previstos en la norma penal lo son de una manera muy abstracta, de modo que dentro de esa actividad abstractamente prevista cabe una amplia gama de conductas concretas. Pensemos, por ejemplo, en la infinidad de conductas que pueden incluirse dentro de la actividad de ejecución típica del homicidio. Es evidente que una determinación de esta manera del hecho procesal es, como mínimo, imprecisa o ambigua ${ }^{61}$. Por tal razón, dentro de la teoría normativa se añade al criterio de la actividad la consideración del objeto material de la tutela penal o, en otras palabras, el resultado lesivo de la acción delictiva (bien jurídico lesionado), de manera de dar un mayor grado de determinación al hecho ${ }^{62}$.

Sin embargo, una parte de la doctrina ${ }^{63}$ insiste en la utilización sólo del criterio de la acción y desecha el criterio del bien jurídico, pues consideran que si se aplicara la exigencia copulativa de ambos ya no bastaría la invariabilidad de la acción para sostener la identidad del objeto procesal, sino que además se requeriría la invariabilidad del bien jurídico (como

terminar siendo sancionada en sentencia como hurto continuado, ya que habría una identidad (parcial) del objeto del proceso. En cambio, si se considera que el delito continuado es una unidad sólo a efectos de evitar la acumulación de pena, que es lo que Bettiol considera correcto, se ha de entender que procesalmente hay pluralidad de hechos distintos, los cuales el juez no podría enjuiciar sin haber sido introducidos por la acusación. Admitir lo contrario implicaría la violación del principio del ne procedat iudex ex officio.

La teoría normativa, en opinión del autor, al distinguir entre hechos sustanciales y adjetivos, transporta al terreno procesal las categorías del hecho penal divididas en esencial y accidental, lo que en su opinión no serviría para resolver la cuestión de la correlación. Y pregunta si se podría entender como elemento sustancial a la acción delictiva. A su juicio esto no es posible porque los elementos de la fattispecie delictiva no gravitan en torno a la acción delictiva, sino en torno a lo que denomina evento, es decir, al resultado de la acción. Para ilustrar la cuestión da el ejemplo del homicidio que se puede haber realizado por un tiro de fusil como por una cuchillada: Tizio può averro perpetratò con un colpo de fucile como con una coltellata. La acción en la dos hipótesis es diversa, por lo que si se requiere la permanencia de una determinada acción a través de todo el proceso debemos concluir que hay una diversidad de hechos si la acusación insiste sobre el disparo de arma de fuego y el juez piensa probado que la muerte fue causada por una cuchillada (Bettiol (1966) pp. 251-252). Por supuesto, este autor distingue a la acción del hecho. Este último -el hecho- además de la acción, abraza al evento o resultado. Parte de su posición, como acabamos de indicar, se basa en la diferenciación entre hecho y acción delictiva sobre la base de que lo subsumido en cada tipo penal no es la acción sino el evento o resultado de la misma. En su teoría, como hemos dicho, el hecho abraza tanto la acción delictiva como al evento o resultado, de modo que habrá un hecho distinto cada vez que se modifique el evento o resultado subsumido a pesar de que provengan de una misma acción, como es el caso del concurso ideal, por ejemplo. Así la existencia de una acusación que sólo se refiere a unos hechos y no a otros en concurso ideal, afecta directamente a la correlación de la sentencia. Este autor requería para salvar la correlación el uso del mecanismo de la notificación verbal de la acusación complementaria y contestación supletoria del artículo 445 del Codice de Procedura penale (derogado) (En el vigente Codice di Procedura Penale la cuestión se resuelve en los artículos 517 con relación al art. 519), con lo cual se produce una acumulación de objetos procesales.

61 Cortés Domínguez (1975) p. 60; Asencio Mellado (1991) p. 78.

62 Vid. Cortés Domínguez (1975) p. 60; Asencio Mellado (1991) p. 78. También las agudas observaciones de La Rocca (1954) pp. 40-62.

63 Vid. Gómez Orbaneja (1951) p. 305-306; Gutiérrez de Cabiedes (1974) pp. 528-529; De la Oliva Santos, A., Derecho procesal penal, cuarta edición. ECERA, Madrid, 1999, pp. 208-211; Cucarella Galiana (2003) pp. 129-136. 
resultado), de modo que si éste se modificara ello afectaría la señalada identidad. Tal situación supondría entonces que el juzgador no podría calificar jurídicamente el hecho de otra manera y modificar el resultado lesivo de la acción (el bien jurídico protegido).

Reconocen, eso sí, que el bien jurídico es útil para justificar la unidad normativa del objeto justo en el caso que dicha identidad no pueda apoyarse en la acción. Sostienen que esto es así en el supuesto de las distintas formas de participación y la autoría. En éstas las acciones del autor y las de los partícipes son totalmente diversas, de modo que no habría unidad normativa sobre la base de la identidad de acción, y, por tanto, unas y otras darían lugar a objetos procesales distintos. De lo anterior se seguiría que la acusación por una de ellas no habilitaría al juez para dictar una sentencia por las otras. Con la finalidad de evitar este efecto limitador sobre los poderes del juez, se acaba utilizando el criterio del bien jurídico en lugar del de la acción, y así poder concluir que existe unidad del objeto normativo también en este caso. Como se ve, esta posición utiliza el bien jurídico como un medio para ampliar los poderes del juez, y no con el propósito de especificar o determinar más precisamente el hecho, según parecía ser el sentido inicial de la teoría. En otras palabras, ¿cómo se puede condenar por complicidad si se acusaba por autoría, cuando entre una y otra no hay ninguna similitud de acción? La justificación está en el bien jurídico: tanto la autoría como la complicidad lesionan un mismo bien jurídico, lo cual justificaría su tratamiento como unidad normativa.

Esta es la opinión de GÓMEZ ORBANEJA ${ }^{64}$, GUTIÉRREZ DE CABIEDES ${ }^{65}$ o DE LA OLIVA $^{66}$. El bien jurídico opera como criterio sustitutorio en aquellos casos en que el objeto

64 Gómez Orbaneja (1951) pp. 305-306.

65 Gutiérrez de Cabiedes (1974) pp. 528-529. Este autor dice que la teoría del objeto normativo definida por el criterio de la acción falla justo en los casos de participación: «Resulta evidente que en estos supuestos el objeto normativo de la autoría es distinto al de la complicidad, y no digamos al del encubrimiento. Los diferentes tipos penales están pensados para los autores y su objeto normativo, o esencia del tipo, abarcará más o menos conductas típicas, pero siempre en grado de autoría. La complicidad o el encubrimiento se penan no por la aplicación de las normas de la parte especial del Código penal, sino por la vigencia de normas específicas de la parte general (arts. 12 a 18) que ensanchan a los cómplices y encubridores la punición que en la parte especial es sólo para los autores» (p. 528).

Y luego agrega: «Abarcando sólo el objeto normativo a los autores, no le sería lícito al juez, aplicando la tesis de LIU, si se acusa a un sujeto como encubridor, castigarlo como autor, ni viceversa».

«En los casos de complicidad, inducción, cooperación, etcétera, el criterio complementario no puede ser otro que el del bien jurídico protegido. ¿Qué hay de común entre matar a otro y colaborar, inducir, auxiliar, etc., al autor de homicidio? Indudablemente, el atentado de diversas maneras contra el bien único protegido: la vida». Con respecto al encubrimiento, apunta: «En el encubrimiento, el elemento de unión no es el bien jurídico protegido. El que oculta, alberga, etc., al delincuente, una vez ocurrida la muerte, no atenta contra la vida. La vida está ya irreparable y definitivamente atacada. Atenta más bien contra la administración de justicia que está interesada en aprehender al delincuente (...) el encubridor comete un delito contra la administración pública y sólo por la conexión que este delito tiene con el principal deducido en juicio, el juez no comete incongruencia, si acusado el imputado, por ejemplo, de encubridor, lo condena como autor» (pp. 528-529). 
Deber de congruencia (rectius, correlación) de la sentencia penal y objeto del proceso:

un problema no resuelto en la ley e insoluble para la jurisprudencia chilena

normativo definido por la acción es insuficiente, que en opinión de estos autores acontece sólo en los casos de participación. Así su concepto de identidad es disyuntivo: «tanto para la correlación de la acusación con la sentencia como para la exclusión del segundo proceso por efecto del primero (bien por litis pendencia, bien por cosa juzgada), debe considerarse que el hecho es el mismo:

1. Cuando existe identidad al menos parcial de los actos de ejecución «típicos»; o

2. Cuando aun sin darse tal identidad, sea el mismo el objeto material del delito».

En contra de esta posición hay otros autores como CORTÉS DOMÍNGUEZ ${ }^{67}$, ASENCIO MELLADO $^{68}$ o PÉREZ MORALES ${ }^{69}$, que efectivamente sí adhieren a la doctrina de la exigencia conjunta de los criterios de acción y bien jurídico. Bien es cierto que sostienen que en determinados casos se ha de aplicar uno u otro criterio exclusivamente, pero en general parten de la idea copulativa o complementaria, reconociendo casos de aplicación exclusiva de uno u otro criterio ${ }^{70}$. ¿Cuáles son los casos específicos? Lamentablemente los que han mantenido esta posición no especifican en qué supuestos se han de aplicar copulativamente y en qué otros sólo uno de ellos. En nuestra opinión, sin embargo, parece lógico suponer que la aplicación copulativa es procedente en la mayoría de los casos en que se trata de hechos penales únicos, mientras que en el caso de pluralidad de hechos penales, como el concurso ideal, pareciera resolverse más bien bajo el criterio de la acción, y, por el contrario, en el caso de las diversas formas de participación se resolvería de forma adecuada bajo el criterio del bien jurídico únicamente.

Con todo, la aplicación copulativa del criterio del bien jurídico lesionado supondrá considerar a éste de un modo distinto al resultado lesivo concreto de la acción delictiva de que se trate. En efecto, si la consideración del bien jurídico permite recoger normativamente el resultado de la acción delictiva y hace posible su valoración procesal con miras a la identificación del hecho, no se les puede considerar equivalentes, ya que ello importaría trasladar sin más el concepto de hecho penal al proceso. Este traslado conduciría a la perniciosa consecuencia de que variaría el resultado -el bien jurídico en concreto- cada vez que se modificara el hecho penal y su correspondiente calificación jurídica, pues cada hecho penal stricto sensu tiene una calificación jurídica diversa que varía cada vez que varía su resultado concreto. Por consiguiente, el juez en ese caso quedaría vinculado no sólo al factum introducido por la acusación, sino

Cortés Domínguez (1975) pp. 59 y ss.

Asencio Mellado (1991) pp. 78-79.

Pérez Morales (2002) pp. 148-151.

Asencio Mellado (1991) p. 80, señala al respecto que «los criterios para la identificación e individualización del hecho procesal se contraen a la acción típica, su resultado, o ambos en común, debiendo optarse en cada caso por uno, otro, o los dos, en función o dependencia del contenido mismo de la acusación». 
además a la concreta calificación jurídica realizada por ésta, privándosele de su poder de aplicación del Derecho al caso concreto. Es por ello que con el fin de evitar esta distorsión normativa es que es menester considerar el bien jurídico lesionado desde una perspectiva abstracta y general como equivalente a aquel bien o bienes tutelados por un conjunto coherente de normas penales pertenecientes a un mismo o próximo ámbito de tutela penal. Con ello junto con evitar el efecto antes señalado, la identidad del bien jurídico lesionado aportará un mayor grado de especificación y delimitación de la significación jurídica de los hechos en que se funda la acusación, impidiendo el mayor grado de indeterminación de la imputación valorada sólo desde una perspectiva de la actividad delictiva. De esta manera sería perfectamente posible pasar de hurto a robo, o de apropiación indebida a estafa, o de lesiones graves a homicidio frustrado, pues en cada uno de esos casos aún cuando el resultado lesivo concreto no es exactamente el mismo, el bien jurídico lesionado desde un punto de vista procesal penal ha de entenderse el mismo, referido, en todos ellos, a un mismo o muy próximos ámbitos de tutela penal. Pero, a la inversa, no se podría pasar de delito de robo con intimidación a delito de amenazas, o delito de robo con violencia a delito de lesiones, pues aún cuando hay pluriofensividad de bienes jurídicos en estos casos y la existencia de una cierta proximidad parcial de los mismos, resulta que el énfasis de la tutela penal y de la significación del resultado lesivo es sustancialmente diverso en unos y otros casos.

Por último, déjese constancia que en dos casos ni siquiera el criterio del bien jurídico sirve para explicar el posible enjuiciamiento único de hechos normativamente distintos. Nos referimos al caso del concurso real y al encubrimiento.

Tanto el concurso real como el encubrimiento suponen hechos distintos, y, además de hechos distintos, ambas figuras no comparten con los otros hechos delictivos la infracción de un mismo bien jurídico. En consecuencia, ninguno de estos dos criterios, la identidad del hecho o la lesión de un mismo bien jurídico ${ }^{71}$, pueden explicar por qué el legislador permite que se enjuicien conjuntamente.

Con respecto al concurso real cabe recordar que éste se constituye como una pluralidad de infracciones producidas por una pluralidad de hechos, realizadas por un mismo autor.

Son dos los fundamentos por los que el legislador permite su enjuiciamiento unitario.

71 Debemos aclarar que esta afirmación de la no unidad de bien jurídico no es totalmente correcta para el concurso real, pues éste abarca ciertas hipótesis de concurso homogéneo por infracciones reiteradas a un mismo bien jurídico, pero que deben tratarse como concurso real o material y no como delito continuado atendido a que, si bien se lesiona un mismo bien jurídico, se trata de un bien de carácter personalísimo o no siendo este personalísimo no concurren en la reiteración delictiva la conexidad delictiva o subjetiva requerida por el delito continuado. 
Deber de congruencia (rectius, correlación) de la sentencia penal y objeto del proceso:

un problema no resuelto en la ley e insoluble para la jurisprudencia chilena

Primero, el penológico-subjetivo, que se halla regulado en el art. 74 del CP, y segundo, la conexidad material existente entre los diversos hechos, configurada en el art. 274 CPP $^{72}$; ambos justifican cabalmente el único juicio para la totalidad de hechos e infracciones.

Con todo, se debe tener claro que en el caso de concurso real lo que se propicia por la Ley es una acumulación de objetos en un único juicio y no la unidad del objeto procesal ${ }^{73}$. En el concurso real cada hecho ilícito constituye un objeto procesal, lo que hace una diferencia de importancia respecto del concurso ideal y que determinará los alcances de la sentencia en cada caso con relación a la cosa juzgada y la litis pendencia. De manera que aquí en realidad no se presenta un genuino problema de identidad o inmutabilidad del objeto del proceso ${ }^{74}$.

Distinto es el caso del encubrimiento. Éste sí se plantea en doctrina como una hipótesis de identidad del objeto del proceso ${ }^{75}$, aunque también el encubrimiento supone unos hechos distintos del delito encubierto y distinto bien jurídico infringido, razón por la cual no sirve ninguno de estos dos criterios para sostener la identidad del objeto.

Cuando se acusa por un delito en autoría o complicidad y se condena por encubrimiento (delito autónomo respecto del delito encubierto) ${ }^{76}$ o viceversa, se hace sobre la base de un

72 La doctrina penal suele poner de relieve este aspecto. Vid. Cobo del Rosal, M., y Vives Antón, T., Derecho penal. Parte general, quinta edición. Tirant lo Blanch, Valencia, 1999, pp. 776-780.

73 Aun cuando en otros ordenamientos esto sea discutible. Roxin (2000) pp. 160-163, señala que ciertos casos de delitos concurrentes pueden ser tratados como una unidad procesal.

74 En la jurisprudencia chilena se ha presentado una situación que parece referirse a la cuestión, aunque con escasa precisión. Nos referimos a la SCS de 3 de enero de 2008, rol 2-2007 (caso Antuco), BDLN, la cual trata de un caso en donde se habría formulado una ambigua acusación por homicidio culposo (entre otros cargos), que la sentencia de instancia castiga como cuasidelito de homicidios reiterados, aplicando las normas del concurso material o real. Inicialmente se podría pensar que formulada la acusación por una calificación de delito único y castigado por una reiteración de delitos (concurso real o material) se está produciendo una clara infracción al deber de correlación, pero lo cierto es que en el caso en cuestión la acusación aparece introduciendo la pluralidad de resultados, pero por una labor de calificación jurídica imprecisa se incurre en la incorrección de acusar sin más por cuasidelito de homicidio sin atender a la pluralidad de resultados de muerte que ella misma introduce y alega en la acusación. Se comprende entonces que aquí se produce un problema independiente del deber de correlación y de identidad de objeto del proceso, que enlaza más bien con la poca calidad en la formulación de las acusaciones.

75 Gutiérrez de Cabiedes (1974) pp. 529-530; De la Oliva Santos (1999) pp. 208-211.

76 En efecto, en las leyes penales más modernas que la chilena se distingue claramente el delito encubierto del encubrimiento, el cual no es tratado como forma de participación en el mismo ilícito, sino como ilícito independiente. Así, por ejemplo, el CPe de 1995 que se ha encargado de ubicarlo dentro del Libro II, Capítulo II, que trata de los delitos contra la administración de justicia. La doctrina moderna también ha establecido lo mismo. Entre muchos, Bustos Ramírez, J., Manual de Derecho penal español. Parte general. PPU, Barcelona, 1984, pp. 341-342; Quintero Olivares, G., Comentarios al nuevo Código Penal. Aranzadi, Pamplona, 1996, pp. 1941-1942. 
hecho distinto y distinto bien jurídico, como lo ha puesto de manifiesto la doctrina penal moderna ${ }^{77}$.

El encubrimiento se integra por un hecho distinto del que constituye el delito encubierto, por la sencilla razón de que la ejecución de aquél tiene lugar una vez que el delito encubierto (su hecho) ha sido ejecutado, y, por esta misma razón, además de distinto, ni siquiera puede ser considerado una forma de participación, ya que no se puede participar en un delito cuya ejecución se ha agotado.

Con respecto a la diversidad de bien jurídico, ello queda claro por la propia naturaleza del encubrimiento, ya que si se considera que, en esencia, esta figura comporta siempre conductas de favorecimiento real o personal ${ }^{78}$ con el fin de que el cómplice, autor o encubridor se aprovechen del delito o eludan la acción de la justicia, se comprende que tanto unas como otras conductas de favorecimiento infringen el bien jurídico de la administración de justicia, con independencia del bien jurídico que protejan los delitos encubiertos en cada caso.

En consecuencia, si por eso debemos descartar como criterios justificadores del enjuiciamiento unitario del encubrimiento a la unidad de acción o identidad de bien jurídico, la única posibilidad que ha vislumbrado la doctrina es, como señala GUTIÉRREZ DE CABIEDES $^{79}$ y DE LA OLIVA SANTOS ${ }^{80}$, la conexidad que existe entre el delito encubierto y el encubrimiento. Esto es lo único que permite justificar, en opinión de los autores citados, que el juzgador pueda condenar por encubrimiento cuando la acusación lo era por autoría o complicidad, o viceversa, siendo hechos totalmente distintos y que protegen distintos bienes jurídicos.

A nuestro juicio, considerar el encubrimiento y el delito encubierto como una unidad de objeto, de modo que el juez pueda pasar de uno a otro sin romper la unidad e identidad del mismo, nos parece francamente excesivo, ya que como pone de manifiesto la doctrina se trata de hechos que nada tienen que ver, ni tampoco sus resultados lesivos. En nuestra opinión, consideramos que debieran ser sometidos al tratamiento de una acumulación de objetos procesales, siendo necesaria la acusación explícita por cada uno de los hechos, quedándole

\footnotetext{
77 Por todos, Bustos Ramírez (1984) pp. 483-484; Quintero Olivares (1996) pp. 1941-1942.

78 Será real cuando se auxilie a los autores o cómplices para que se beneficien del provecho o se aprovechen ellos mismos de los efectos del delito, art. $17 \mathrm{n}^{\circ} 1$ del CP; será personal cuando se oculte, altere o inutilice el cuerpo, los efectos o los instrumentos del delito, o se ayude a los presuntos responsables a eludir la investigación o a sustraerse de su busca y captura, art. $17, \mathrm{n}^{\circ} 2,3$ y $4 \mathrm{CP}$.

79 Gutiérrez de Cabiedes (1974) pp. 529-530.

80 De la Oliva Santos (1999) pp. 208-211.
} 
Deber de congruencia (rectius, correlación) de la sentencia penal y objeto del proceso:

un problema no resuelto en la ley e insoluble para la jurisprudencia chilena

vedado al juez enjuiciar el encubrimiento cuando se haya acusado sólo por el hecho encubierto, o viceversa. Así lo estima ROXIN ${ }^{81}$ para el caso alemán.

\section{MÁS ALLÁ DE LA CORRELACIÓN: EL PROBLEMA DEL OBJETO DEL DEBATE NO SE RESUELVE CON LA TEORÍA DEL HECHO PARA LA CORRELACIÓN Y, POR LO TANTO, DEMANDA UN TRATAMIENTO SEPARADO}

Más allá del hecho punible desde un punto de vista procesal normativo, es decir, más allá del objeto del proceso, se sitúa el problema del derecho de defensa y del principio de contradicción, los cuales alcanzan a todas las cuestiones fácticas y jurídicas del caso. En efecto, las partes tienen derecho a defenderse y a contradecir no sólo respecto del hecho sustancial de que trata el proceso, sino además respecto de todos los hechos y circunstancias fácticas tengan o no eficacia jurídico-penal, y además respecto de todos los aspectos referidos a la calificación jurídica y la consecuencia punitiva. Todos esos contenidos se aglutinan en el objeto del debate, el cual delimita el ámbito, la amplitud del derecho de defensa y la eficacia del principio de contradicción. Como se ve, su ámbito es mucho mayor al del objeto del proceso ${ }^{82}$.

Suele ocurrir en los procesos penales que diversos aspectos que componen el objeto del debate registren en la secuela del procedimiento variaciones en su configuración concreta: aparecen o desaparecen elementos fáctico y/o jurídicos que afectan o influyan sobre la calificación jurídica o las consecuencias punitivas que derivan de ésta o que, simplemente, puedan pesar en la plausibilidad probatoria de la imputación-acusación que se enjuicia. Desde un punto de vista técnico es perfectamente posible que dichas modificaciones puedan ser introducidas por las partes o incluso de oficio por el juez, y, adviértase, ello no importa ninguna infracción al deber de correlación, pues, de lo contrario, se estaría instaurando un sistema rígido de preclusión de alegaciones, inexistente en Derecho comparado. Con todo, esto importará una especial preocupación por los medios para que se introduzcan esas modificaciones fácticas y jurídicas al proceso, con el fin de que con ello no se causen lesiones no ya al deber de correlación (principio de congruencia), sino al derecho de defensa y principio de contradicción con relación al ámbito o amplitud con que estos deben ser aplicados, es decir, con relación al objeto del debate.

Lamentablemente, salvo el restringido cauce de la tesis del art. 341 CPP para la introducción de modificaciones previa advertencia del juzgador, la Ley procesal chilena incurre en una grave imprevisión normativa. Parece que la Ley procesal quisiera establecer un sistema rígido

\footnotetext{
$81 \quad$ Roxin (2000) pp. 162-163.

82 Del Río Ferretti (2007) passim.
} 
de preclusión acusatoria sobre la base de un acto acusatorio anterior al resultado probatorio, inmodificable, no actualizable a los resultados de la prueba.

Todo lo precedente sólo puede comprenderse cabalmente si se vuelve sobre un problema que últimamente ha quedado al descubierto en nuestra jurisprudencia, como es la necesidad de distinguir entre objeto del proceso y objeto del debate, para tener claridad de lo que se debe hacer con los denominados hechos accidentales o accesorios, que siendo tales no son relevantes para la determinación del objeto procesal desde una perspectiva normativa.

Como crítica general al sistema chileno en este aspecto podemos decir que la extrema rigidez en la regulación de la preclusión acusatoria tal cual parece estar prevista en la Ley procesal chilena, con un único acto de acusación formulado antes de la práctica de la prueba sin posibilidades reales de ajustes al resultado probatorio supondría desconocer la técnica utilizada en ordenamientos técnicamente más afinados como el italiano, alemán o español, y con ello, lo peor de todo, se generarán situaciones de difícil resolución contrarios al espíritu general de la reforma procesal.

Con ello se acota de manera forzada la formulación de la acusación, la cual, como mínimo, debería ser actualizada a los resultados probatorios del juicio: en último término la acusación en su formulación final debería asumir las modificaciones fácticas, siempre en el entendido de la inalteración del objeto del proceso. De lo contrario, la negación de esto implicará por regla general dos posibilidades, cada cual insatisfactorias. La primera de ellas consiste en entender que el deber de correlación se encuentra tan estrictamente formulado que cualquiera modificación introducida en la sentencia, por insignificante que ella sea, lesiona el deber de correlación de ésta con la acusación inicial, lo cual no sería sino una (mala) forma de resolver el problema de la imposibilidad de ajustar la acusación al resultado probatorio, pues sólo de esa manera la preclusión acusatoria sería capaz de obrar como límite eficaz, delimitador eficaz de los poderes de resolución jurisdiccional: de lo contrario, el juez de forma repentina introduciría en el último momento modificaciones fácticas no asumidas e introducidas por la acusación que podrían alterar el objeto del proceso o, sin alterarlo, podrían provocar lesiones al derecho de defensa por modificaciones al objeto del debate, como es el caso de la introducción de hechos accidentales. Esta ha sido la alternativa o solución que inicialmente parecía imponerse en buena parte de la doctrina jurisprudencial sin muchos matices. Se tendía a considerar de manera extrema la correlación, sobre la base de una preclusión rígida en la formulación de la acusación, lo cual importaba la total inmodificabilidad (inmutabilidad) de los hechos de la acusación inicial. Ésta quedaba rígidamente definida antes del juicio y esa delimitación operaba en forma absoluta. Con esta solución se produjeron fallos aberrantes: se dictaron sentencias de absolución por modificaciones en la ubicación temporal del hecho (error en una fecha) o de un dato espacial (cambios del lugar de acaecimiento), o por la modificación de la modalidad concreta de comisión, elementos fácticos claramente irrelevantes desde el punto de vista del objeto del proceso. Bien es verdad, eso sí, que en casos concretos una circunstancia histórico-natural puede tener 
Deber de congruencia (rectius, correlación) de la sentencia penal y objeto del proceso:

un problema no resuelto en la ley e insoluble para la jurisprudencia chilena

relevancia ya no por su trascendencia para el objeto del proceso, sino en función del derecho de defensa, pero ello podría haber sido resuelto justamente a través de la técnica de configuración flexible y progresiva de la acusación con posibilidades de ampliación del debate y prueba durante el desarrollo del proceso (juicio oral), vía que no parece todavía vislumbrada por la jurisprudencia.

La otra forma de enfrentar el problema (insatisfactoria así mismo) es aquella que tiende a imponerse en la más reciente jurisprudencia. En ella también se parte de la preclusión estricta del acto de acusación del art. $259 \mathrm{CPP}$, pero frente a esa preclusión producida antes de la práctica de la prueba no se está dispuesto a dejar limitado de manera extrema al juez, al punto de llegar a las situaciones de pronunciar absoluciones por cambios de lugar, de tiempo o de modalidad comisiva, con todas las consecuencias que ello conlleva. Para ello se ha acudido a una concepción normativa simplificada e imprecisa sobre el hecho: se esgrime la teoría normativa del hecho -sin mucha claridad- a efectos de correlación. Se afirma, de este modo, que el juez se halla limitado por el hecho procesalmente relevante definido por el núcleo esencial del mismo (aunque nunca se diga cuál es ese núcleo), pero no por esos fragmentos o circunstancias fácticos accesorios jurídicamente irrelevantes (rectius, accidentales). Con esa afirmación general e imprecisa la jurisprudencia suele resolver sin más la cuestión, llegando a la conclusión de que los hechos o circunstancias accesorios pueden ser introducidos o modificados por el juez en la sentencia.

La solución a la que se puede llegar con este criterio puede ser parcialmente correcta respecto al deber de correlación, pero olvida por completo que hechos accidentales y, por lo tanto, irrelevantes a efectos de objeto del proceso pueden tener importancia jurídico-penal ${ }^{83} \mathrm{o}$, sin ella, pueden ser importantes a efectos de la determinación del objeto del debate y de la eficacia del derecho de defensa. La introducción tardía en la sentencia definitiva privaría a la defensa de ampliar su defensa a los nuevos términos del objeto del debate con necesidad incluso de nueva prueba.

Justamente un ejemplo claro de lo que se viene diciendo, entre otros del último tiempo, subyace al problema de la SCS de 24 de diciembre de 2007, rol 5415-2007, en la cual se rechaza el recurso de nulidad interpuesto por la imputada en contra de una sentencia de condena por parricidio frustrado. El caso, en lo que nos interesa, es el siguiente: los hechos de la acusación

La jurisprudencia chilena del último tiempo tiende, como se ha visto, a realizar una consideración simplificada e incorrecta de la teoría normativa del hecho, como si ésta importara la inmutabilidad de todos los elementos fácticos que producen efectos penales, los cuales serían considerados relevantes o sustanciales, y, por el contrario, irrelevantes o accesorios (rectius, accidentales) aquellos que no producen dichos efectos penales. Para demostración del error de este concepto «normativo» de hecho nos remitimos a lo ya dicho acerca de las posiciones normativas. 
sostienen que en un día determinado la madre de la víctima, de profesión médico-cirujano, ingresa clandestinamente al hospital y a la habitación de la víctima (su hijo), que en ese momento se hallaba hospitalizado, y sin autorización ni conocimiento del equipo médico tratante le suministra fármacos al margen del tratamiento médico, lo que le causa un súbito y severo deterioro de sus funciones vitales que implicó hipoglicemia, inestabilidad hemodinámica y desadaptación al ventilador, presentando un edema pulmonar que hizo necesario efectuar diversas maniobras de reanimación, dado que sus signos vitales variaron repentinamente de rangos, principalmente la presión venosa central, funciones respiratorias y funciones cardíacas, todo lo cual, de no haber mediado oportuna intervención de facultativo, habría producido la muerte de la víctima.

A este conjunto de hechos la sentencia impugnada habría añadido explícitamente el fármaco preciso suministrado y la dosis del mismo. En concepto del tribunal de instancia estos elementos que él añade carecen de trascendencia jurídica para la determinación de una eventual infracción al deber de correlación. La sentencia con ello, si bien puede estar en lo cierto en cuanto al carácter accesorio (accidental) de los hechos añadidos con relación al objeto del proceso y fines de correlación, elude de forma palmaria la repercusión que el asunto puede tener con relación a la determinación del objeto del debate, pues debería de haberse tenido en cuenta que los hechos siendo normativamente accesorios y por lo tanto susceptibles de ser introducidos por el juez pueden lesionar la posición procesal de defensa o alterar su eficacia, frente a lo cual habría que asegurar un mecanismo de debate contradictorio para la introducción de esas modificaciones fácticas. Esto último es lo que habría de asegurarse a través del mecanismo del debate contradictorio, articulado por la posibilidad de ajustar la acusación al resultado probatorio con la consiguiente y correlativa oportunidad de la defensa de responder (refutar) y, en su caso, introducir nueva prueba, ya que, como en el ejemplo, el conocimiento del fármaco preciso o su modificación, la dosis suministrada o la modalidad de suministro pueden generar toda una línea de discusión nueva acerca de la verdadera eficacia letal de aquello.

Por todo lo dicho es que es tan importante considerar el problema en toda su amplitud. No se resuelve todo con un concepto simplista de hecho; por el contrario, es menester hacer precisiones sobre el hecho y luego sobre esa base distinguir bien el problema de la correlación y objeto del proceso, por una parte, y el debate contradictorio y objeto del debate, por otra.

Justamente por estas razones o, con precisión, por la falta de consideración de estas cuestiones es que la CS resuelve sólo de forma parcialmente correcta el problema cuando dice que no hay lesión del deber de correlación, pero siendo esto correcto, olvida que no acaba allí el problema; que la introducción de hechos en la sentencia que no toca a la correlación del hecho puede en todo caso afectar el derecho de defensa en cuanto la introducción intempestiva en sentencia puede lesionar su posición jurídica de defensa: la eficacia y amplitud de su defensa, como parece ser el caso en cuestión, lo cual se intuye por el voto de minoría de la SCS citada (Ministro Dolmetsch). 
Deber de congruencia (rectius, correlación) de la sentencia penal y objeto del proceso:

un problema no resuelto en la ley e insoluble para la jurisprudencia chilena

Se entiende con lo explicado la importancia de regular adecuadamente la preclusión acusatoria y el interés técnico que tiene el disponer de oportunidades procesales posteriores a la prueba para ajustar el contenido acusatorio, aparejando a ello oportunidades de ampliar el debate probatorio.

\section{BIBLIOGRAFÍA}

AGÜERO HERRERA, Melquisedec (1965): Congruencia entre la acusación, la defensa y la sentencia (Santiago, Edit. Universitaria) 116 pp.

ASENCIO MELLADO, José María (1991): Principio acusatorio y derecho de defensa en el proceso penal (Madrid, Trivium) $136 \mathrm{pp}$.

BAUMANN, Jürgen (1989): Derecho procesal penal. Conceptos fundamentales y principios procesales (traducción de la tercera edición ampliada, por Conrado Finzi, Buenos Aires, Depalma) 299 pp.

BERNER (1891): Der Grundsatz des ne bis in idem im Strafprozess, Leipzig.

BETTIOL, Giuseppe (1966): «La correlazione fra accusa e sentenza nel processo penale», en: Scritti giuridici, tomo I (Padova, Cedam) pp. 222-306.

BUSTOS RAMÍREZ, Juan (1994): Manual de Derecho penal español. Parte general, (Barcelona, PPU) 614 pp.

CALAMANDREI, Iolanda (1996): «Diversità del fatto e modifica dell'imputazione nel Codice di Procedura penale del 1988», en Rivista di Diritto e Procedura penale (Milano, Giuffrè) pp. 634-657.

CASTRONUOVO, Donato (2002): «La contestazione del fatto colposo: discrasie tra formule prasseologiche d'imputazione e concezione teoriche della colpa», Cassazione penale, fascicolo 12, diciembre de 2002, pp. 3834-3846.

COBO DEL ROSAL, Manuel y VIVES ANTÓN, Tomás (1999): Derecho Penal. Parte general, quinta edición (Valencia, Tirant lo Blanch) 998 pp.

CORDERO, Franco (1958): «Considerazioni sul principio d'identità del fatto», en Rivista italiana di diritto e procedura penale (Milano, Giuffrè) pp. 935-945.

CORDERO, Franco (2001): Procedura penale, sexta edición (Milano, Giuffrè) 1336 pp.

CORTÉS DOMÍNGUEZ, Valentín (1975): La cosa juzgada penal (Bolonia, Publicaciones del Real Colegio de España) 205 pp.

CORTEZ MATCOVICH, Gonzalo (2006): El recurso de nulidad. Doctrina y jurisprudencia, segunda edición (LexisNexis, Santiago) 422 pp.

CUCARELLA GALIANA, Luis (2003): La correlación de la sentencia con la acusación y la defensa (Aranzadi, Cizur Menor) $306 \mathrm{pp}$.

DE LA OLIVA SANTOS, Andrés (1999): Derecho procesal penal, cuarta edición (ECERA, Madrid) $935 \mathrm{pp}$.

DEL RÍO FERRETTI, Carlos (2007): La correlación de la sentencia con la acusación y la defensa. Estudio comparado del Derecho español con el chileno (Valencia, Servicio de Publicaciones de la Universidad de Valencia) (versión cederrón) 745 pp. 
EICHHORN, «Non bis in idem und das Reichsgericht», en Gerichtsaal, Band 38. FENECH, Miguel (1945): Derecho procesal penal, tomo I (Barcelona, Bosch). FENECH, Miguel (1945): Derecho procesal penal, tomo III (Barcelona, Bosch). FLORIÁN, Eugenio (1932): Parte generale del diritto penale, Milano.

FONTECILLA RIQUELME, Rafael (1978a): Tratado de Derecho procesal penal, tomo II, segunda edición (Santiago, Edit. Jurídica de Chile) 527 pp.

FONTECILLA RIQUELME, Rafael (1978b): Tratado de Derecho procesal penal, tomo III, segunda edición (Santiago, Edit. Jurídica de Chile) 406 pp.

GIANNITI, Pasquale (1999): «Rilievi sul «fatto» nel processo penale», en Rivista italiana de Diritto e procedura penale (Milano, Giuffrè) pp. 408-433.

GIARDA, Angelo y SPANGHER, Giorgio (2001): Codice di procedura penale. Comentario, segunda edición (Milano, IPSOA).

GÓMEZ ORBANEJA, Emilio (1947): Comentarios a la Ley de Enjuiciamiento Criminal, tomo I (Barcelona, Bosch) 606 pp.

GÓMEZ ORBANEJA, Emilio (1951): Comentarios a la Ley de Enjuiciamiento Criminal, tomo II (Barcelona, Bosch) 793 pp.

GÖSSEL, Karl Heinz (2007): «Acerca del normativismo y del naturalismo en la teoría de la acción», en Derecho penal comtemporáneo. Revista internacional, 21, octubre-diciembre de 2007 (traducción de Miguel Polaino-Orts y José Caro John), 153-171 pp.

GUTIÉRREZ DE CABIEDES, Eduardo (1974): «La correlación entre acusación y sentencia», en Estudios de Derecho procesal (Pamplona, EUNSA) pp. 517-537.

LANG (1910): Die Rechstshängigkeit im Strafverfahren, Leipzig.

LARENZ, Karl (2001): Metodología de la Ciencia del Derecho (traducción de Rodríguez Molinero, Barcelona, Ariel) 536 pp.

LA ROCCA, Manlio (1954): Studi sul problema del «fatto» nel processo penale, (Napoli, Eugenio Jovene) $122 \mathrm{pp}$.

MANZINI, Vicenzo (1914): Trattato di procedura penale italiana, Volumen II, (Milano, Torino, Roma, Fratelli Bocca Editori).

MANZINI, Vicenzo (1953): Tratado de Derecho Procesal Penal, Volumen IV, (Traducido por Sentís Melendo y Ayerra Redín, Buenos Aires, EJEA).

MEZA FIGUEROA, Pablo (1969): De la ultra petita en el proceso penal chileno, (Santiago, Edit. Jurídica de Chile) 111 pp.

PÉREZ MORALES, Mónica Galdana (2002): Correlación entre acusación y sentencia en el proceso ordinario. Doctrina y jurisprudencia (Granada, Comares) $256 \mathrm{pp}$.

QUINTERO OLIVARES, Gonzalo (1996): Comentarios al nuevo Código Penal, en: VV.AA (Pamplona, Aranzadi) 2387 pp.

RAFARACI, Tommaso (1996): Le nuove contestazione nel processo penale (Milano, Giuffrè) $539 \mathrm{pp}$.

RIEUTORD ALVARADO, Andrés (2007): El recurso de nulidad en el nuevo proceso penal (Santiago, Edit. Jurídica de Chile) 257 pp.

ROMERO SEGUEL, Alejandro (2004): Jurisprudencia de los tribunales como fuente del 
Deber de congruencia (rectius, correlación) de la sentencia penal y objeto del proceso:

un problema no resuelto en la ley e insoluble para la jurisprudencia chilena

Derecho. Una perspectiva procesal (Santiago, Edit. Jurídica de Chile) 149 pp.

ROXIN, Claus (2000): Derecho procesal penal (traducción de Córdoba y Pastor, Buenos Aires, Editores del Puerto) 601 pp.

SCHMIDT, Eberhard (1957): Los fundamentos teóricos y constitucionales del Derecho procesal penal (traducción de José Manuel Nuñez, Buenos Aires, Depalma) 358 pp.

SPANGHER, Giorgio y GIARDA, Angelo (2001): Codice di procedura penale. Comentario, segunda edición (Milano, IPSOA).

VÁZQUEZ SOTELO, José Luis (1984): «El principio acusatorio y su reflejo en el proceso penal español», en Revista Jurídica de Catalunya, No 2, pp. 373-418.

VERGER GRAU, Joan (1994): La defensa del imputado y el principio acusatorio, (Barcelona, Bosch) 180 pp.

VIVES ANTÓN, Tomás y COBO DEL ROSAL, Manuel (1999): Derecho Penal. Parte general, quinta edición (Valencia, Tirant lo Blanch) 998 pp.

\section{JURISPRUDENCIA ORDENADA POR ÓRGANO JURISDICCIONAL}

\section{Jurisprudencia de la Corte Suprema}

SCS de 7 de mayo de 1913, GT, 1913, 1er semestre, No 282, p. 887.

SCS de 5 de junio de 1922, GT, 1922, $2^{\circ}$ semestre, $N^{\circ} 101$, p. 481.

SCS de 3 de junio de 1932, GT, 1932, 1er semestre, No 62, p. 201.

SCS de 18 de abril de 1933, GT, 1933, 1er semestre, No 53, p. 241.

SCS de 3 de junio de 1935, GT, 1935, 1er semestre, $N^{\circ}$ 65, p. 301.

SCS de 25 de mayo de 1937, GT, 1937, 1er semestre, No 75, p. 312.

SCS de 1 de septiembre de 1942, RCP, 1943, tomo 6, p. 195.

SCS de 4 de agosto de 1943, RCP, 1943, tomo 6, p. 444.

SCS de 25 de septiembre de 1944, GT, 1944, $2^{\circ}$ semestre, No 32, p. 151.

SCS de 2 de noviembre de 1944, GT, $2^{\circ}$ semestre, No 37 , p. 171.

SCS de 9 de agosto de 1946, GT, 1946, $2^{\circ}$ semestre, $N^{o}$ 48, p. 305.

SCS de 15 de octubre de 1948, GT, 1948, $2^{\circ}$ semestre, No 60, p. 347.

SCS de 10 de enero de 1952, RDJC, tomo 49, secc. $4^{\text {a }}$, p. 56.

SCS de 9 de septiembre de 1953, RDJC, tomo 50, secc. $4^{\mathrm{a}}$, p. 160.

SCS de 9 de agosto de 1956, RDJC, tomo 53, secc. $4^{\circ}$, p. 92.

SCS de 6 de noviembre de 1961, RDJC, tomo 58, secc. $4^{\text {a }}$, p. 283.

SCS de 17 de abril de 1963, RDJC, tomo 60, secc. $4^{\text {a }}$, p. 91.

SCS de 6 de mayo de 1963, RDJC, tomo 60, secc. $4^{\text {a }}$, p. 202.

SCS de 4 de septiembre de 1963, RDJC, tomo 60, secc. $4^{\mathrm{a}}$, p. 403.

SCS de 14 de septiembre de 1964 , RDJC, tomo 61 , secc. $4^{\mathrm{a}}$, p. 363.

SCS de 13 de septiembre de 1966, RDJC, tomo 63, secc. $4^{\text {a }}$, p. 245.

SCS de 27 de abril de 1967, RDJC, tomo 64, secc. $4^{\text {a }}$, p. 95.

SCS de 27 de julio de 1967, RDJC, tomo 64, secc. $4^{\text {o }}$, p. 161.

SCS de 26 de octubre de 1967, RDJC, tomo 64, secc. $4^{\text {a }}$, p. 299.

SCS de 27 de octubre de 1967, RDJC, tomo 64, secc. 4º, p. 302. 
SCS de 26 de octubre de 1967, RDJC, tomo 64, secc. $4^{\text {a }}$, p. 302.

SCS de 1 de abril de 1968, RDJC, tomo 65, secc. $4^{\mathrm{a}}$, p. 63.

SCS de 19 de abril de 1972, RDJC, tomo 69, secc. $4^{\text {a }}$, p. 31.

SCS de 13 de noviembre de 1990, RDJC, tomo 87, secc. $4^{\mathrm{a}}$, p. 133.

SCS de 15 de diciembre de 1992, GJ, 1992, No 150, volumen 2, pp. 69-70.

SCS de 15 de diciembre de 1992, FM, N 409, p. 949.

SCS de 23 de septiembre de 2005, rol 3297-2005, BDLN.

SCS de 24 de diciembre de 2007, rol 5415-2007.

SCS de 3 de enero de 2008, rol 2-2007 (caso Antuco), BDLN.

\section{Jurisprudencia de las Cortes de Apelaciones}

SCA de La Serena, de 28 de junio de 1940, RDJC, 1940, p. 181.

SCA de Santiago, de 7 de agosto de 1940, GT, 1940, $2^{\circ}$ semestre, No 96, p. 437.

SCA de Santiago, de 10 de noviembre de 1955, RDJC, tomo 52, secc. 4a, p. 114.

SCA de Temuco, de 11 de septiembre de 1964, RDJC, tomo 61, secc. $4^{\mathrm{a}}$, p. 350.

SCA de Santiago, de 1 de agosto de 1984, GJ, 1984, No 49, pp. 116-117.

SCA de Santiago, de 19 de junio de 1986, RDJC, tomo 83, secc. $4^{\text {a }}$, p. 152.

SCA de Santiago, de 2 de julio de 1987, RDJC, tomo 84, secc. $4^{\text {a }}$, p. 98.

SCA de Santiago, de 19 de octubre de 1988, RDJC, tomo 85, secc. $4^{\mathrm{a}}$, p. 180.

SCA de San Miguel, de 28 de septiembre de 1989, RDJC, tomo 86, secc. 4a, p. 142.

SCA de Santiago, de 12 de septiembre de 1990, RDJC, tomo 87, secc. $4^{\mathrm{a}}$, p. 137.

SCA de Punta Arenas, de 16 de junio de 1993, RDJC, tomo 90, secc. $4^{\mathrm{a}}$, p. 157.

SCA de Santiago, de 18 de abril de 1995, GJ, No 178, p. 133.

SCA de Santiago, de 22 de septiembre de 1995, RDJC, secc. $4^{\text {a }}$, p. 248.

SCA de Santiago, de 14 de enero de 1997, GJ, 1997, No 199, volumen 1, pp. 141-142.

SCA de la Serena, de 11 de diciembre de 2001, Rol Corte n. 133.

SCA de Temuco, de 13 de octubre de 2003, rol 323-2003.

SCA de Copiapó, de 23 de abril de 2004, rol 2-2004.

SCA de Serena, de 30 de marzo de 2005, rol 50.

SCA de Serena, de 8 de abril de 2005, rol 57.

SCA de Santiago, de 29 de marzo de 2006, rol 232-2006, BDLN.

SCA de Santiago, de 4 de julio de 2007, rol 1308, BDLN.

SCA de Santiago, de 3 de agosto de 2007, rol 1121-2007, BDLN.

SCA de Copiapó, de 24 de septiembre de 2007, rol 128-2007, BDLN.

SCA de Concepción, de 24 de septiembre de 2007, rol 416-2007, BDLN.

SCA de Concepción, de 6 de diciembre de 2007, rol 586-2007, BDLN.

SCA de Concepción, de 14 de diciembre de 2007, rol 601-2007, BDLN.

\section{Jurisprudencia de los Tribunales del juicio oral en lo penal}

STJO de Antofagasta, de 16 de noviembre de 2002, rol interno 44-2002.

STJO de Antofagasta, de 20 de mayo de 2003, rol interno 30-2003. 
STJO de Antofagasta, de 10 de agosto de 2003, rol interno 70-2003.

STJO de Copiapó, de 23 de diciembre de 2003, rol interno 66-2003.

STJO de Antofagasta, de 15 de septiembre de 2004, rol interno 106-2004.

STJO de Antofagasta, de 17 de septiembre de 2004, rol interno 93-2004.

STJO de Rancagua, de 18 de noviembre de 2004, rol interno 67-2004, BDLN.

STJO de Rancagua, de 18 de junio de 2005, rol interno 60-2005, BDLN.

STJO de Iquique, de 10 de febrero de 2005, rol interno 293-2004, BDLN.

STJO de Arica, de 20 de septiembre de 2005, rol interno 53-2005, BDLN.

STJO de Cauquenes, de 9 de noviembre de 2005, rol interno 22-2005, BDLN.

STJO de Santiago $\left(7^{\circ}\right)$, de 18 de enero de 2006, rol interno 3-2005, BDLN.

STJO de Santiago (1 $1^{\text {a }}$ Sala), de 4 de abril de 2006, rol interno 15-2006.

STJO de San Felipe, de 6 de febrero de 2008, rol interno 63-2007. 
126 Revista Ius et PraXis - AÑo 14 - № 2 